\title{
A Recent Study Concerning the Climatic Variability over the Kingdom Saudi Arabia for the Period 1948-2018
}

\author{
Yehia Hafez \\ Department of Meteorology, King Abdulaziz University, Jeddah, KSA \\ Email: ysalam@kau.edu.sa
}

How to cite this paper: Hafez, Y. (2019). A Recent Study Concerning the Climatic Variability over the Kingdom Saudi Arabia for the Period 1948-2018. Journal of Geoscience and Environment Protection, 7, 268-289.

https://doi.org/10.4236/gep.2019.78020

Received: July 9, 2019

Accepted: August 24, 2019

Published: August 27, 2019

Copyright $\odot 2019$ by author(s) and Scientific Research Publishing Inc. This work is licensed under the Creative Commons Attribution International License (CC BY 4.0).

http://creativecommons.org/licenses/by/4.0/

\section{c) (i) Open Access}

\begin{abstract}
The present paper provides a recent study of the climatic variability over the Kingdom of Saudi Arabia (KSA) for the period 1948-2018. Moreover, for that period, the relationship of this climatic variability over KSA with the climatic indices is studied. The NCEP/NCAR Reanalysis monthly data sets of the meteorological and climatic parameters over the KSA for the period from the year 1948 to the year 2018 are used. The parameters are (air temperature at levels of 1000 hpa and $500 \mathrm{hpa}$, mean sea level pressure, geopotential height at $500 \mathrm{hpa}$ level, surface relative humidity, precipitation rate, and outgoing longwave radiation). In addition, the monthly data of climatic indices (North Atlantic Oscillation index (NAO), Arctic Oscillation (AO), Southern Oscillation Index (SOI), Nino 3.4, Global Mean Surface Air Temperature (GMST)) are used. The time series trend, anomaly method, and correlation coefficient techniques are used for data analysis. The results revealed that the annual meteorological and climatic parameters vary dramatically from year to year through the period of study (1948-2018). The trend of this variation is a positive trend for the temperature, pressure and outgoing longwave radiation parameters over KSA. Meanwhile, it is a negative trend of the annual values of surface humidity and precipitation over KSA. The climatic indices influence and control the distribution of annual meteorological and climatic parameters over KSA. The highest significant correlation recorded is between the mean annual of climatic parameters over KSA and the climatic index of global mean surface air temperature (GMST).
\end{abstract}

\section{Keywords}

Climatic Variability, Climatic Indices, KSA

\section{Introduction}

The Kingdom of Saudi Arabia (KSA) suffered from abnormal variability of cli- 
mate Athar (2015). The climate variability is a phenomenon occurring worldwide, which has caused major changes in climate variables such as precipitation, air temperature, relative humidity, and solar radiation (Tirkey et al., 2018). The KSA climate is exactly dry. However, the distribution and the values of meteorological and climatic parameters vary distinctly over KSA (Abdullah \& Al-Mazroui, 1998; Kwarteng et al., 2009; El-Nesr et al., 2010; Hasanean \& Almazroui, 2015; Hag-elsafi \& El-Tayib, 2016; Hafez, 2016; Saeed \& Almazroui, 2019). For precipitation, the KSA recorded large amounts of rainfall in the northern, central-north, and southwest regions. Whereas the southeast region is dry. Moreover, the southwest region of the country receives rainfall in almost all months (Almazroui et al., 2012). Recently, Saeed and Almazroui (2019) found a link between mid-latitude circumglobal wave train (CGT) and winter precipitation over the Arabian Peninsula. For the temperature, distribution over KSA Almazroui (2012) found that the strong variability in surface air temperature over Saudi Arabia is close with the North Atlantic Oscillation (NAO) index for all seasons except the autumn season. Moreover, this connection is most prominent during winter. The study shows that winter temperature is influenced by the Arctic Oscillation (AO) index, whereas the El Nino Southern Oscillation (ENSO) influences spring temperature. However, the KSA climate varies greatly significantly depending on the geographic position. The KSA climate varies from season to season and is instructed by the atmospheric circulation (Donat et al., 2013; Hasanean \& Almasroui, 2015; Kang et al., 2015; Hafez, 2016, 2018). In fact, the horizontal distribution pattern of rainfall during autumn over the KSA is somewhat similar to that during spring (Mashat \& Abdel Basset, 2011). However, there are several worldwide scientific works of literature that challenge the teleconnection between the climatic variability of weather and climatic conditions and the climatic indices (e.g., Barriendos \& Llasat, 2003; Hafez, 2008; Hafez \& Robaa, 2008; Iona et al., 2015). However, in Ghana, the Southern Oscillation Index (SOI) is used for enhancing rainfall prediction and agricultural water management (Adiku \& Stone, 1995). The ability to forecast rainfall over Australian based on the (SOI) phase system was examined for Australian rainfall Cobon and Toomb (2013). From the earlier studies of Lorenz (1950) and Kutzbach (1970), Thompson and Wallace (1998), Thompson et al. (2000) it is found that impressive evidence for the importance of the weather and climate pattern of variability of the climatic index of the Arctic Oscillation (AO). In addition to that, the weather and climatic patterns are highly correlated with the North Atlantic oscillation (NAO) pattern (Wallace \& Gutzler 1981; Hurrell, 1995; Wallace, 2000; Hafez, 2008). The patterns of AO and NAO distinction could play a guiding role in how to understand the physical mechanisms in the Northern Hemisphere variability (Ambaum et al., 2001). The AO inference of the weather and climate for several regions over the northern hemisphere (Gong \& Wang, 1999; Thompson et al., 2000; Hines \& Bromwich, 2002; Gong \& Ho, 2003; Overland \& Wang, 2005; Sun \& Huijun, 2006; Choi \& Byun, 2010). Almazroui (2012) 
found that the interannual variability of the mean air temperature of KSA indicates a warming phase that started in the late 1990s following global warming indications. Moreover, the strong variability in temperature over KSA is closely associated with the NAO index mainly through the winter season. El Nino Southern Oscillation Index (ENSO), AO and NAO indices play a great role in the temperature increase over the country. Analyses of the global mean surface air temperature (GMST) change carried out by several groups, including the NASA Goddard Institute for Space Studies. It has become clear that global warming is continuing unabated. Hafez (2008) found that there is a significant teleconnection between the global mean surface air temperature and precipitation over Europe. Goddard and Dilley (2005) found that the ENSO phenomenon generates a significant proportion of short-term climate variability globally in general. It is found that the SOI and rainfall can be predicted in short terms using time series analysis methods Tularam (2010). Hafez (2016) found that KSA climate parameters, temperature and precipitation rates controlled by the Oceanic Nino Index (ONI). Tarawneh and Chowdhury (2018) found that, in most regions of KSA, for the climatic scenario, the representative concentration pathway RCP6, for the period 2045-206. It appears that a decrease in rainfall from the reference period (1986 to 2005). The present work aims to study the annual climate variability over the kingdom, Saudi Arabia for the period (1948-2018). Moreover, to that, the relationship between the annual variability of climatic meteorological parameters over KSA and the climatic indices [North Atlantic Oscillation index (NAO), Arctic Oscillation (AO), Southern Oscillation Index (SOI), Nino 3.4, global mean surface air temperature (GMST)] through the period (1948-2018) has studied.

\section{Data and Methodology}

\subsection{Data}

The National Centers for Environmental Prediction/National Center for Atmospheric Research (NCEP/NCAR) Reanalysis project is using a state-of-the-art analysis/forecast system to perform data assimilation, within resolution of $2.5^{\circ} \times$ $2.5^{\circ}$ degree lat/long grid, using past data from 1948 to 2018. Monthly data sets of air temperature at levels of $1000 \mathrm{hpa}$ and $500 \mathrm{hpa}$, mean sea level pressure, geopotential height at 500 hpa level, relative humidity, precipitation rate and outgoing longwave radiation over KSA for the period from the year of 1948 to the year of 2018 is used. In addition, the monthly data of climatic indices [north Atlantic oscillation index (NAO), arctic oscillation (AO), southern oscillation index (SOI), Nino 3.4, global mean surface air temperature (GMST)] through the period (1948-2018) are used. In fact, the data of AO are available for the period (1950-2018) only. These data sets provided by the NOAA/OAR/ESRL PSD, Boulder, Colorado, USA and (Kalnay et al., 1996). These data sets obtained from the website through the internet of the Climate Prediction Centre at http://www.cpc.ncep.noaa.gov/products/monitoring_data/. However, NCEP da- 
ta sets of weather and climatic parameters domain considered in the present work extended to $12^{\circ} \mathrm{N}-32^{\circ} \mathrm{N}, 33^{\circ} \mathrm{E}-60^{\circ} \mathrm{E}$ for KSA, see Figure 1 .

\subsection{Methodology}

The methods used in the present work for data analysis are the time series, Anomaly method, and linear correlation coefficient techniques. The climatic mean values of the weather and climatic parameters taken through the period (1981-2010). Whereas, the period of climatic mean must be a 30 -year mean. Moreover, the climatic mean through the period (1981-2010) is the recent worldwide use of climatic mean for climatological studies. The linear correlation coefficient techniques used to obtain the relationship between the climatic variability of the meteorological parameters over KSA through the period (1948-2018) and the climatic indices.

\subsubsection{Calculation of Annual Averages}

The calculations of annual averages of the weather and climatic parameters for each grid point in the domain of KSA, [ $9 \times 12$-degree lat/long grids] done. The annual averages of these parameters over the KSA are calculated. Using the NCEP/NCAR reanalysis monthly data sets for each month through the year from January to December (12 months/12). The climatic mean of the meteorological parameters taken for the period (1981-2010). The monthly data of climatic indices [NAO, AO, SOI, NINO3.4, and GMST] through the period (1948-2018) for the annual calculated in the same manner. However, the interactive plotting and analysis NCEP/NCAR software program is the use of these analyses.

\subsubsection{Linear Correlation Method}

In fact, for the purpose of the present study, a linear correlation analysis of the climatic parameters and the climatic indices through the period 1948-2018 used for the present analysis. The methodology of Monte-Carlo has been used, (Livezey \& Chen 1983). Statistically, based on this methodology, a correlation of 0.2

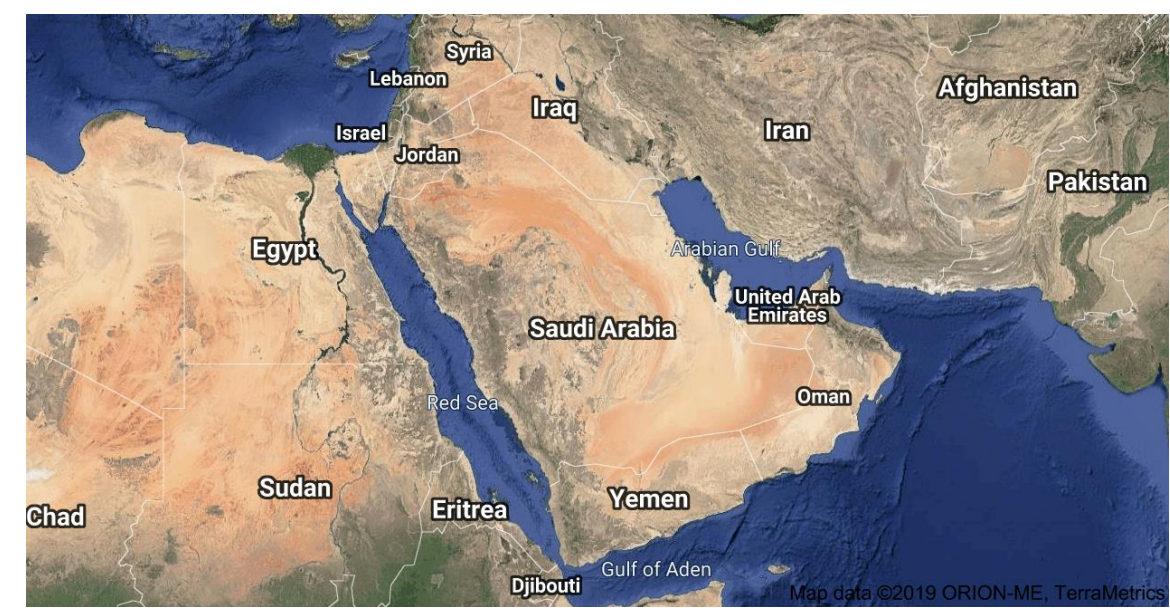

Figure 1 . The study area of $\mathrm{KSA}$ region $\left[12^{\circ} \mathrm{N}-32^{\circ} \mathrm{N}, 33^{\circ} \mathrm{E}-60^{\circ} \mathrm{E}\right]$. 
would be significant for degrees of freedom 66. In addition to that, the linear correlation method according to Livezey and Chen (1983) and Diaconis and Efron (1983) is used. The statistical significance was determined using the Kendall-tau test. According to that test, a trend deemed to "statistically significant" if it has at least $90 \%$ significance.

\subsubsection{Local Significance and Calculation of Correlation Patterns}

For given annual means of the meteorological parameter at each grid point correlated with the previous annual mean of the climatic indices. Each grid point correlation was t-tested for local significance using (Philips, 1996) allowing for temporal autocorrelation according to (Livezey \& Chen, 1983) method. We use the Monte-Carlo methodology to estimate the correlation. However, the field significance statistic is the area-weighted average absolute correlation of a given correlation map. Whereas, the field-significance threshold is the 95th percentile of a 1000-member Monte-Carlo population.

\section{Results and Discussion}

\subsection{The Annual Variability of Climatic Parameters over KSA through the Period (1948-2018)}

The NCEP/NCAR Reanalysis monthly data sets of air temperature at levels of $1000 \mathrm{hpa}$ and $500 \mathrm{hpa}$, mean sea level pressure, geopotential height at $500 \mathrm{hpa}$ level, relative humidity, precipitation rate and outgoing longwave radiation over KSA for the period (1948-2018) for annual values are analyzed using of the anomaly method and the linear trend techniques. The results revealed that:

1) The time series analysis of temperature anomaly at level 500 hpa shows that through the period (1948-1997) the temperature varies almost less than its normal values. Meanwhile, it has a value more than its normal values from the year of 1998 to the year of 2018. The trend of the temperature anomaly is a positive trend through the study period (1948-2018). As shown in Figure 2(a).

2) Analysis of temperature anomaly at level $500 \mathrm{hpa}$ appears that the values of temperature anomaly fluctuate sharply from year to year through the study period and it is becoming more than its normal values mainly through the period (1998-2018). The trend of the temperature anomaly is a positive trend through the period of study (1948-2018). The trend of temperature is a positive trend as shown in Figure 2(b).

3) Time series analysis of sea level pressure anomaly revealed that its values are less than its normal values for the period (1948-1975). Meanwhile, for the period (1977-1997) it becomes more than its normal in general. Almost of the period (1998-2018) has mean sea level pressure less than its normal values. There is a positive trend of mean sea level pressure through the period of study (1948-2018), as illustrated in Figure 3(a).

4) The time series analysis of the geopotential height at $500 \mathrm{hpa}$ level uncovered that there are two distinct periods. The first one (1948-1977) has a negative anomaly of geopotential height. Second one (1979-2018) period has a 


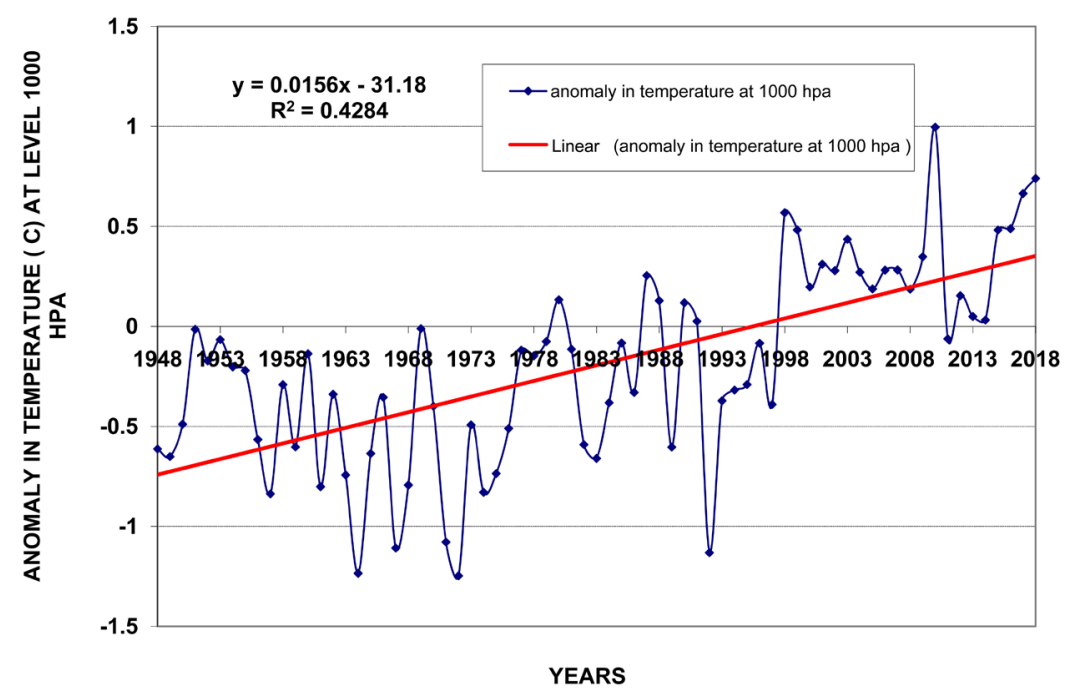

(a)

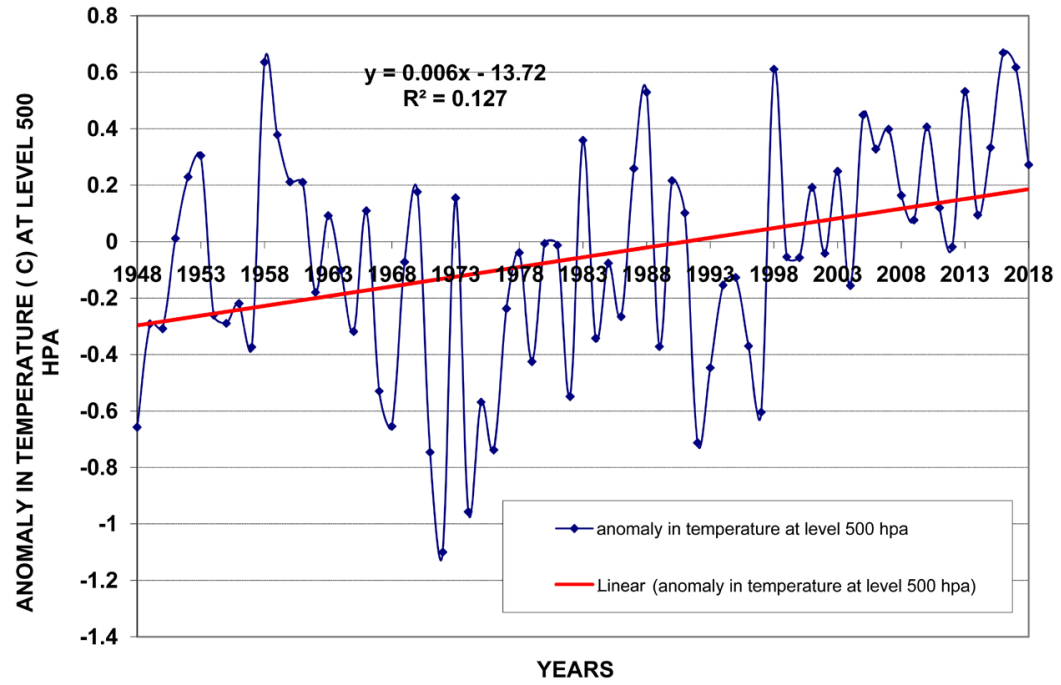

(b)

Figure 2. The time series of the annual anomaly variation in temperature $\left({ }^{\circ} \mathrm{C}\right)$ over KSA (a) at pressure level of $1000 \mathrm{hpa}$; (b) at pressure level of $500 \mathrm{hpa}$ through the period (1948-2018).

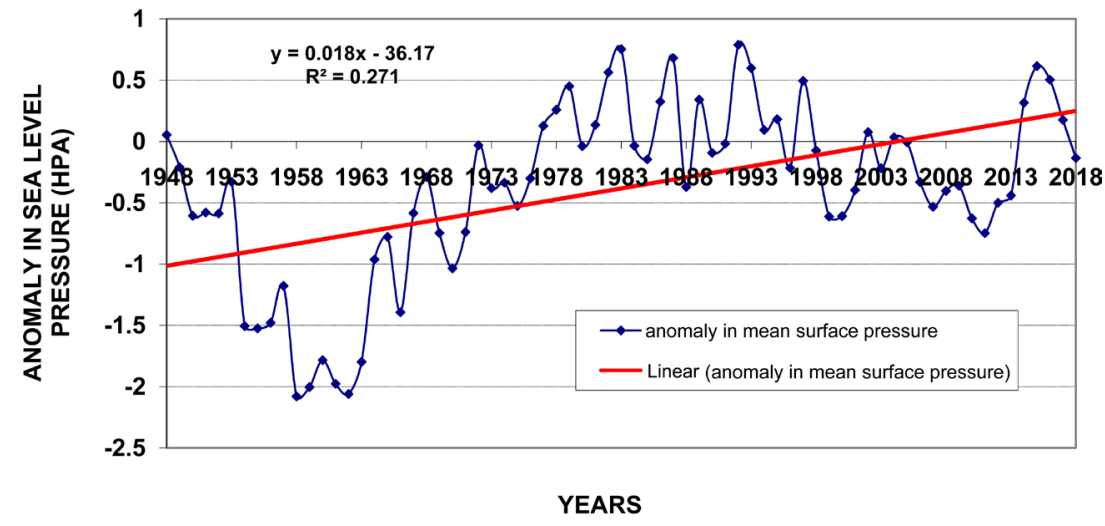

(a) 


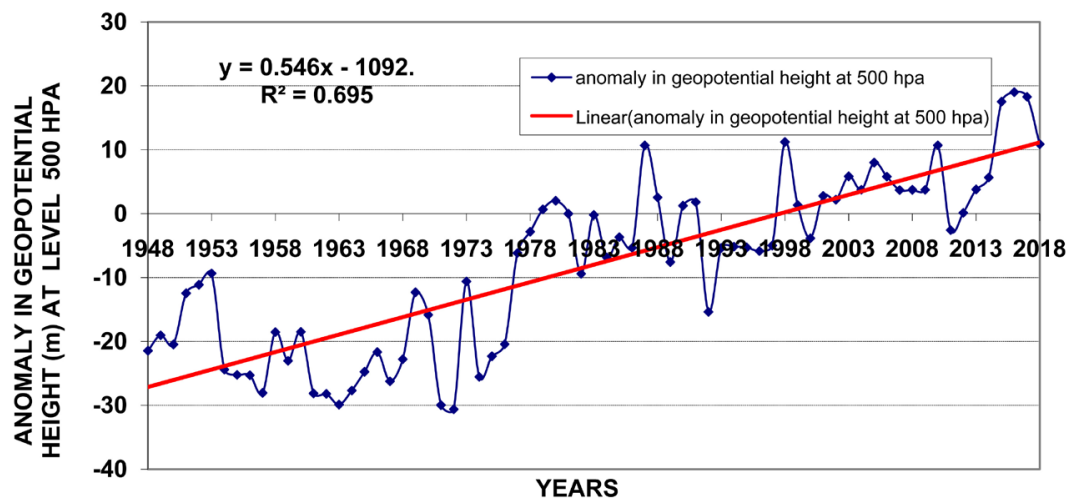

(b)

Figure 3. The time series of the annual anomaly variation in pressure over KSA. (a) Mean sea level pressure (hpa); (b) Geopotential height at pressure level of 500 hpa through the period (1948-2018).

positive anomaly of geopotential height in general, as shown in Figure 3(b). The trend of geopotential height variability is a positive trend.

5) The time series analysis of relative humidity anomaly illustrates that there is a sharp decrease of relative humidity through the study period (1948-2018). The trend of relative humidity is a negative trend through the period of study see Figure 4(a).

6) Time series analysis of annual precipitation amounts appears that there is a sharp decrease of it within a sharp negative trend during the period of study (1948-2018), as illustrated in Figure 4(b).

7) Analysis of the annual outgoing longwave radiation anomaly shows that there is a sharp increase of it through the study period (1948-2018). The trend of its variation with time is a sharp positive trend, as clear from Figure 5.

\subsection{Study the Relationship between the Annual Climatic Parameters over KSA and Climatic Indices through the Period (1948-2018)}

The composite mean of the correlation coefficient of reanalysis monthly data sets of the [air temperature at levels of $1000 \mathrm{hpa}$ and $500 \mathrm{hpa}$, the mean sea level pressure, geopotential height at $500 \mathrm{hpa}$ level, relative humidity, precipitation rate and outgoing longwave radiation] over KSA for the period (1948-2018) has been done. This correlation with the climatic indices (NAO, AO, SOI, NINO3.4, and GMST) for the years of the present study (1948-2018). The composite mean of the correlation coefficient of the climatic parameters over KSA and climatic indices for annual variations has analyzed for the period of study. The results revealed that:

\subsubsection{The Relationship between the Climatic Parameters over KSA and the NAO Index}

For the annual mean of air temperature at $1000 \mathrm{hpa}$ level, it is clear that there is negative significant correlation coefficient exist between the 1000 hpa level air 


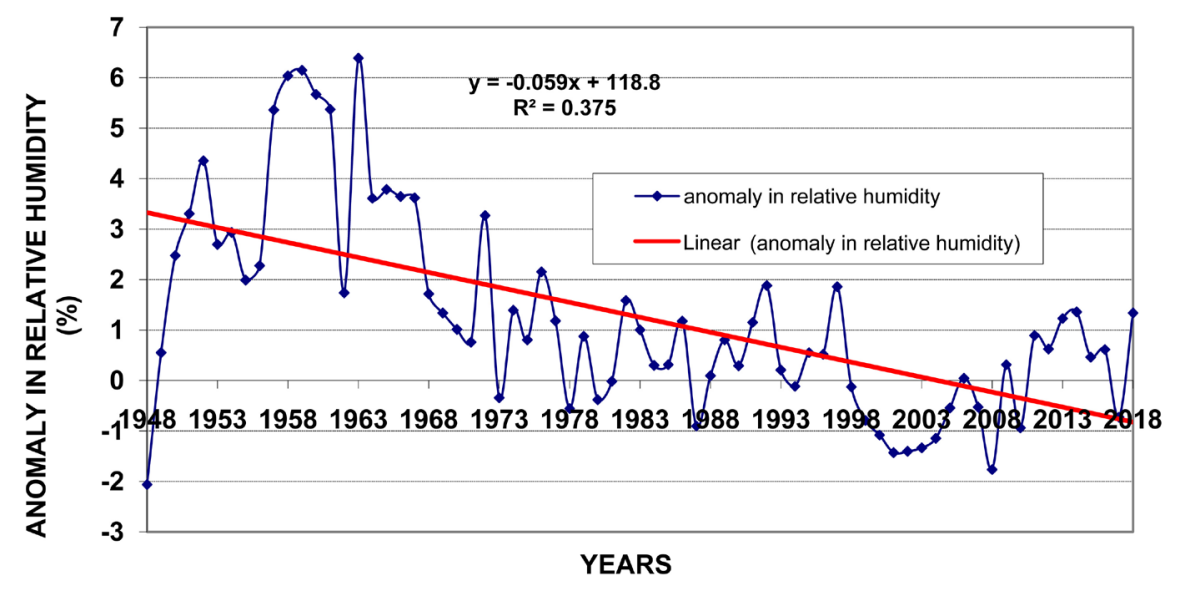

(a)

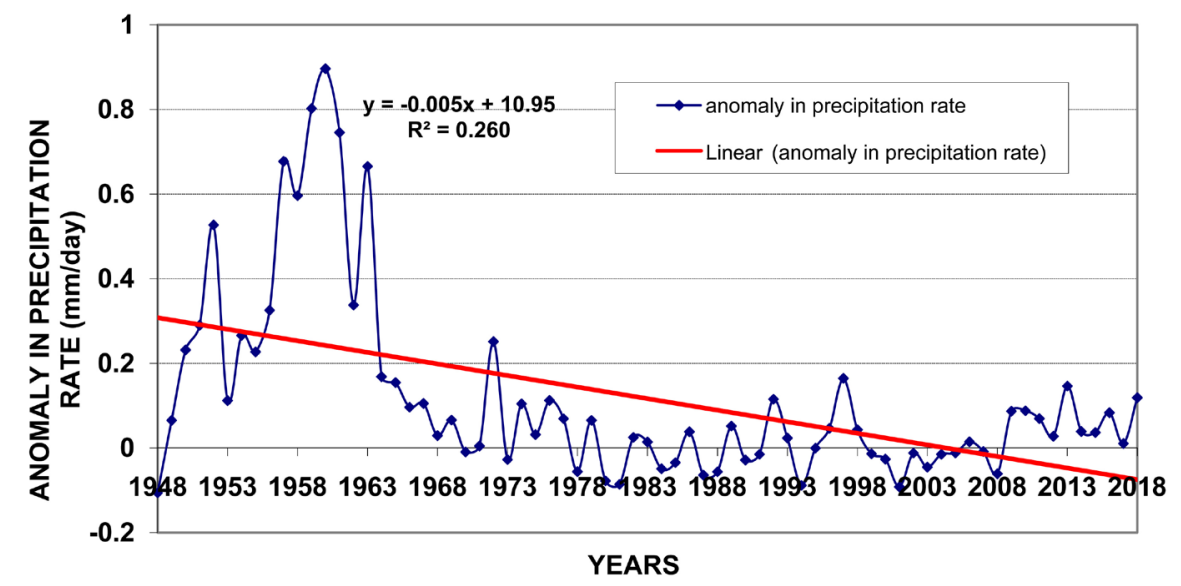

(b)

Figure 4. The time series of the annual anomaly variation over KSA of: (a) relative humidity (\%); (b) precipitation rate (mm/day) through the period (1948-2018).

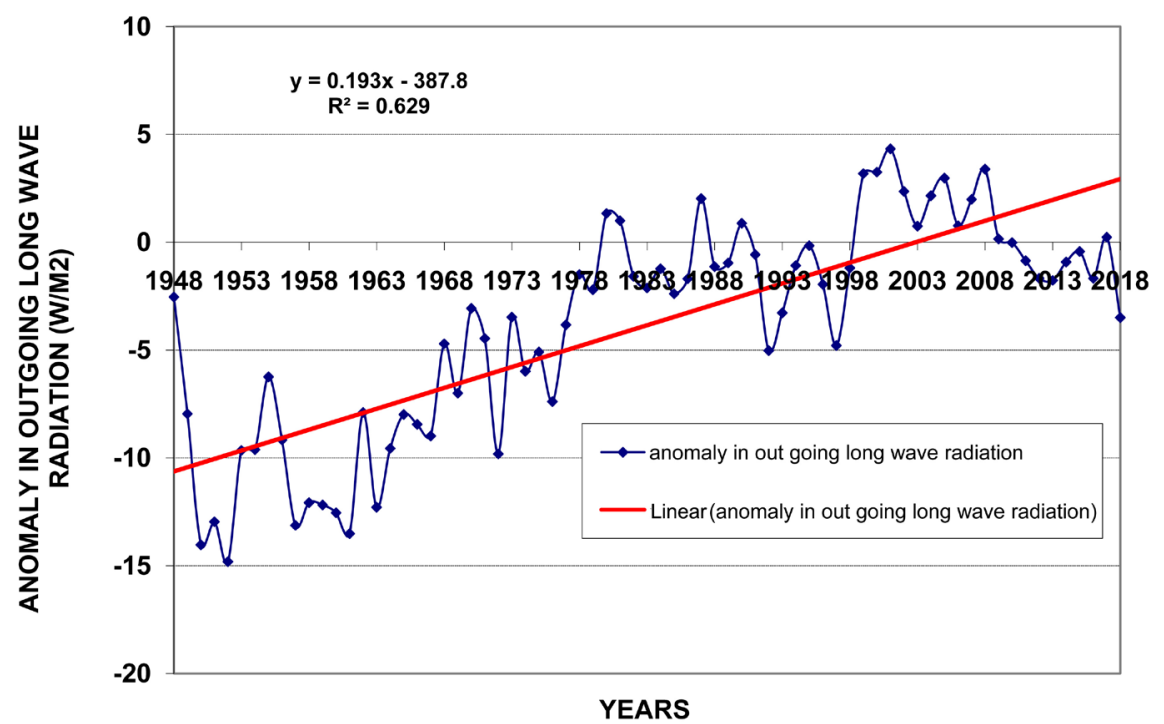

Figure 5. The time series of the annual anomaly variation in outgoing long wave radiation $\left(\mathrm{W} / \mathrm{M}^{2}\right)$ over KSA through the period (1948-2018). 
temperature (-0.3) over the norther part of KSA and the North Atlantic Oscillation index NAO. See Figure 6(a) and Table 1. In addition to that there is a significant negative correlation of $(-0.3)$ between the annual mean temperature at 500 hpa level and the NAO over the northern part of KSA through the study period (1948-2018) as clear from Figure 6(b) and Table 1.

1) The value of correlation coefficient between the mean annual of mean sea level pressure is $(+0.4)$ with the climatic index NAO over the KSA through the period (1948-2018). As it shown from, Figure 6(c) and Table 1.

2) There is a positive correlation of $(+0.2)$ between the mean annual values of geopotential height at level of 500 hpa and the climatic index NAO over the southern part of KSA as clear from Figure 6(d) and Table 1.

3 ) It is found that there is a negative correlation coefficient $(-0.2)$ between the annual mean of the relative humidity and the climatic index NAO over the southwestern part of KSA. As illustrated in Figure 6(e) and Table 1.

4) For the precipitation rate it is found that there is a significant negative correlation coefficient $(-0.3)$ between the annual mean of the precipitation rate and the climatic index NAO over the northern part of KSA. As illustrated in Figure 6(f) and Table 1.

$5)$ It is found that a notably positive correlation coefficient $(+0.2)$ between the outgoing longwave radiation over the south of KSA and the climatic index NAO. As shown in Figure 6(g) and Table 1.

\subsubsection{The Relationship between the Climatic Parameters over KSA and the AO Index}

1) For the annual mean of air temperature at 1000 hpa level, it is clear that there is negative significant correlation coefficient exist between the $1000 \mathrm{hpa}$ level air temperature (-0.4) over the north of KSA and the Arctic Oscillation index AO. See Figure 7(a) and Table 1. Moreover, there is an outstanding negative correlation of $(-0.3)$ between the annual mean temperature at $500 \mathrm{hpa}$ level and the AO over the west and north part of KSA as clear from Figure 7(b) and Table 1.

Table 1. The correlation coefficient matrix between the annual climatic parameters over KSA and the climatic indices through the period (1948-2018).

\begin{tabular}{|c|c|c|c|c|c|}
\hline \multirow{2}{*}{$\begin{array}{c}\text { Correlation coefficient } \\
\text { Climatic parameters } \\
\text { Over KSA }\end{array}$} & \multicolumn{5}{|c|}{ Climatic indices } \\
\hline & NAO & $\mathrm{AO}$ & SOI & NINO3.4 & GMST \\
\hline TEMPERATURE AT 1000HPA LEVEL & $-0.3^{* * *}$ & $-0.4^{* * *}$ & -0.1 & $+0.3^{\star * *}$ & $+0.8^{\star}$ \\
\hline TEMPERATURE AT 500 HPA LEVEL & $-0.3^{\star * *}$ & $-0.3^{* * *}$ & -0.2 & +0.2 & $+0.5^{\star *}$ \\
\hline SEA LEVEL PRESSURE & $+0.4^{* * *}$ & $+0.5^{\star \star}$ & $-0.6^{\star *}$ & $+0.5^{\star *}$ & $+0.5^{\star *}$ \\
\hline GEOPOTENTIAL HEIGHT AT GPH500 HPA LEVEL & +0.2 & +0.2 & $-0.3^{\star * *}$ & $+0.4^{\star * *}$ & $+0.8^{\star}$ \\
\hline RELATIVE HUMIDITY & -0.2 & $-0.3^{\star * *}$ & -0.2 & +0.2 & $-0.5^{\star *}$ \\
\hline PRECIPITATION RATE & $-0.3^{* * *}$ & $-0.3^{* * *}$ & -0.2 & $+0.3^{* * *}$ & $-0.3^{\star * *}$ \\
\hline OUTGOING LONGWAVE RADIATION & +0.2 & $+0.3^{* * *}$ & +0.1 & 0.0 & $+0.7^{*}$ \\
\hline
\end{tabular}

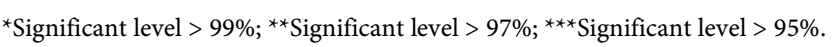




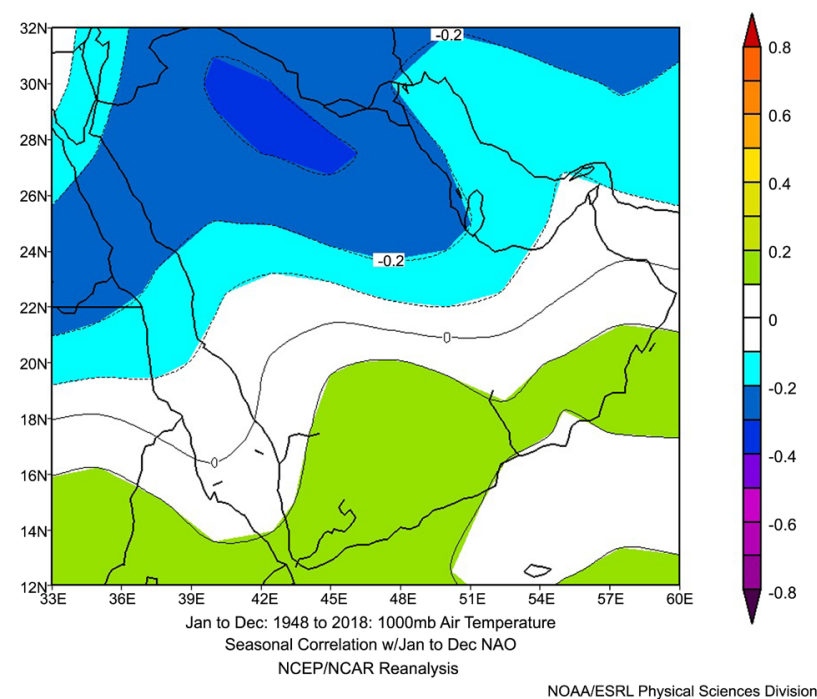

(a)

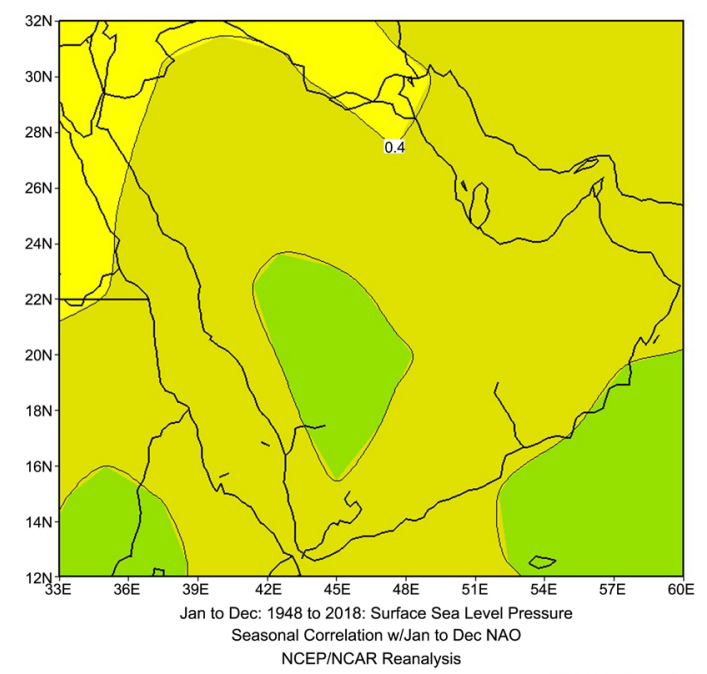

(c)

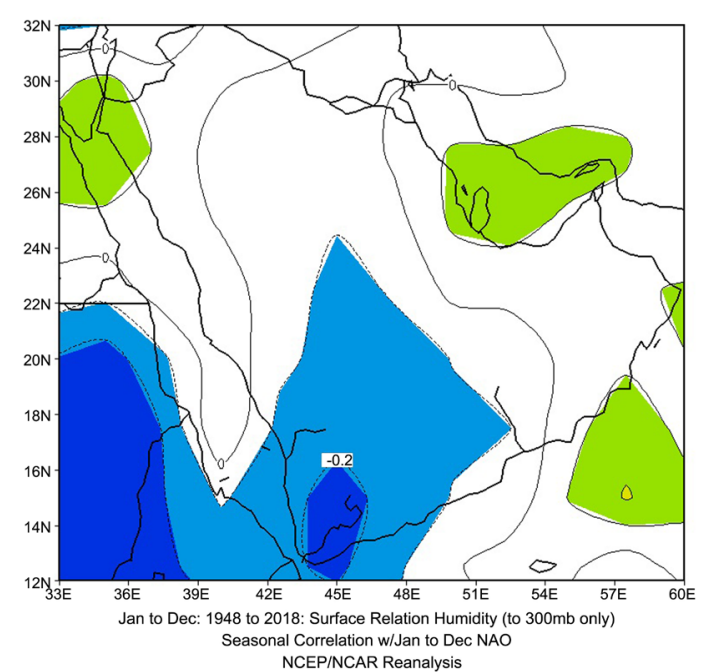

(e)

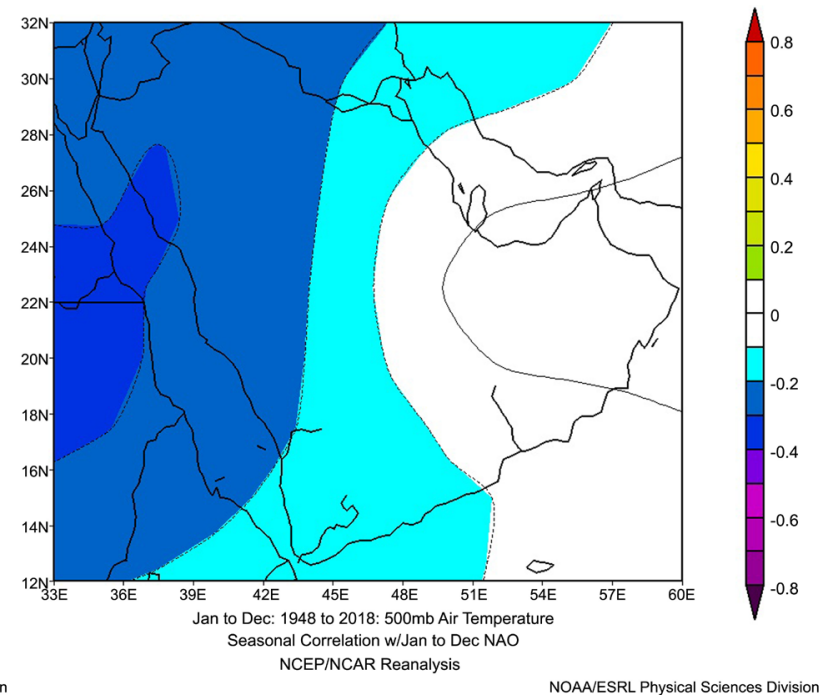

(b)
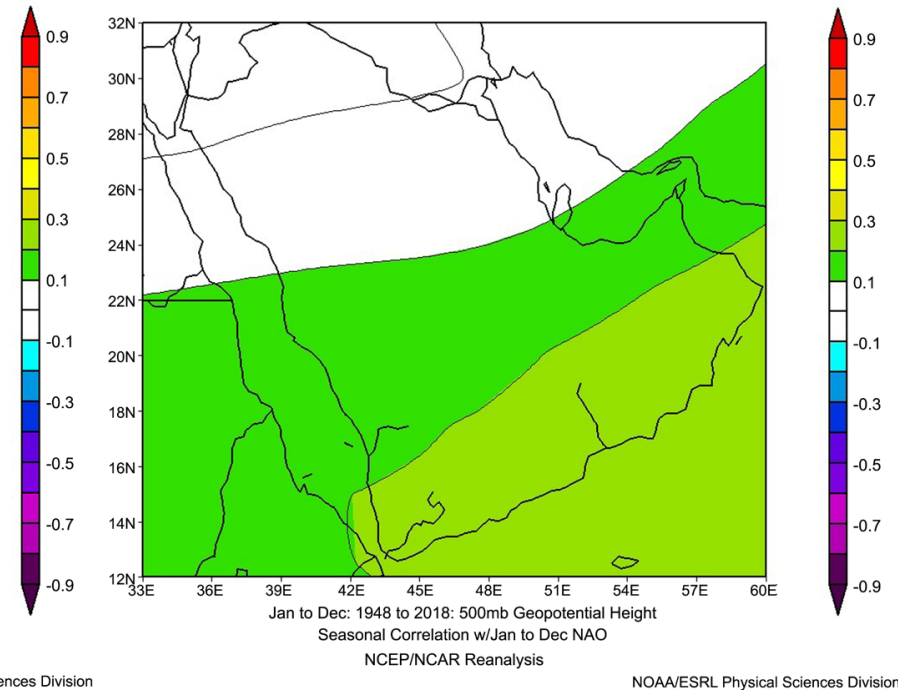

(d)

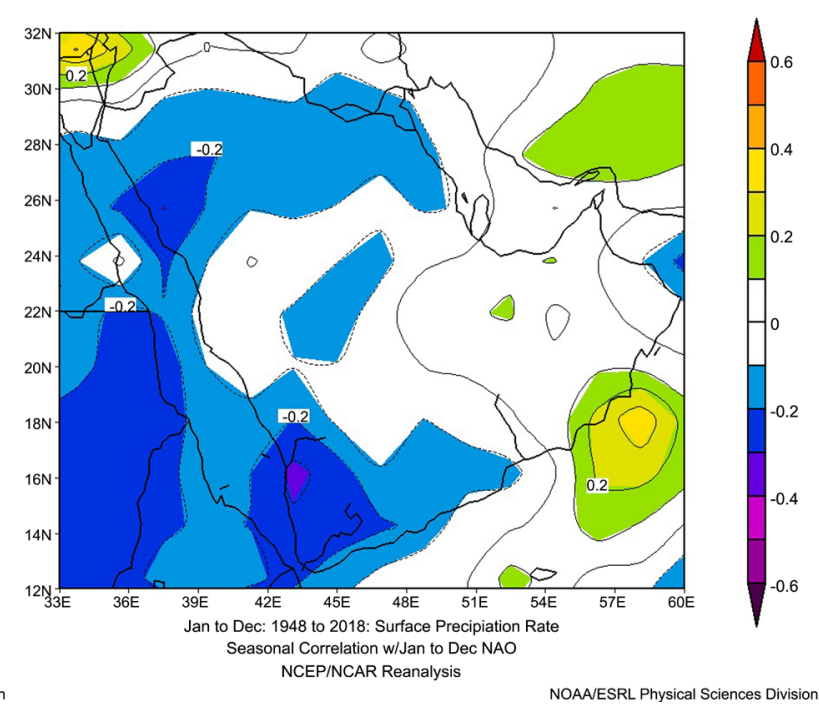

(f) 


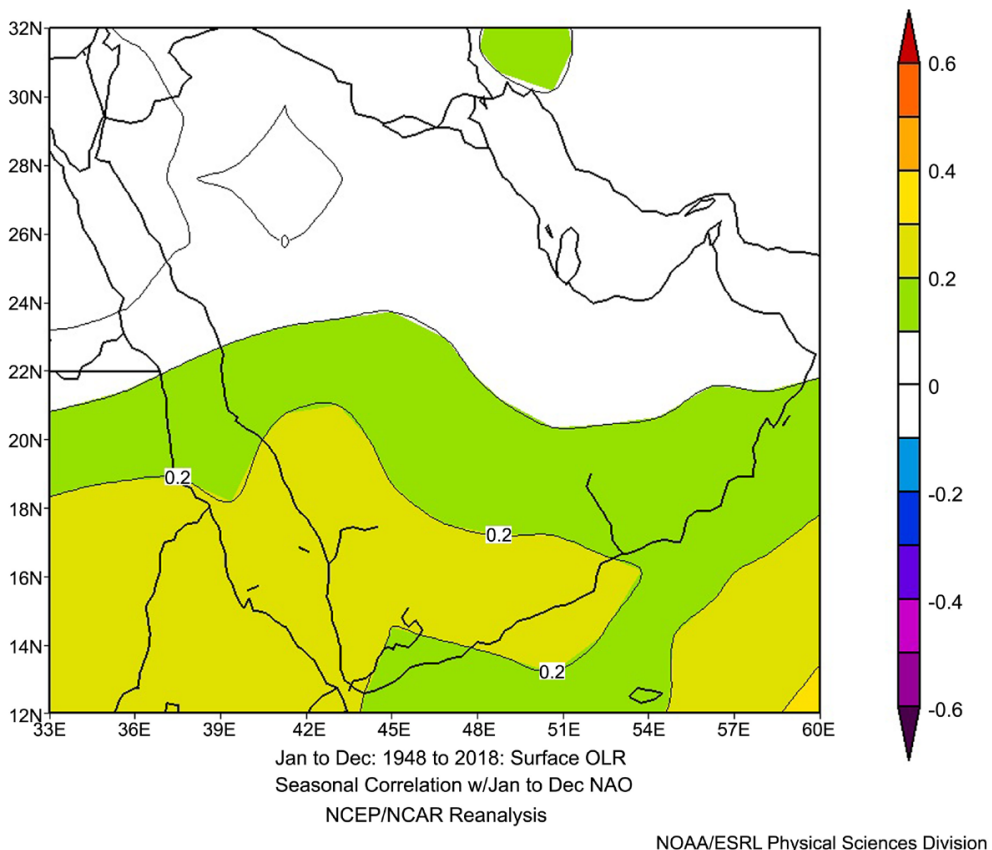

(g)

Figure 6. The composite of correlation coefficient between the annual distribution of climatic parameters (TEMP1000 HPA, TEMP500 HPA, MSLP, GPH500 HPA, RH, PRECIP and OLR) over KSA and the climatic index NAO through the period (1948-2018).

2) There is a high significant positive correlation coefficient between the mean annual of mean sea level pressure is $(+0.5)$ with the climatic index AO over the northern part of KSA. As it shown from, Figure 7(c) and Table 1.

$3)$ It is clear that, there is a significant positive correlation of $(+0.3)$ between the mean annual values of geopotential height at level of $500 \mathrm{hpa}$ and the climatic index AO over the southern and central part of KSA as clear from Figure 7(d) and Table 1.

4) It is found that there is a negative correlation coefficient $(-0.3)$ between the annual mean of the relative humidity and the climatic index $\mathrm{AO}$ over almost of KSA. As illustrated in Figure 7(e) and Table 1.

5) For the precipitation rate it is noticed that there is a high significant negative correlation coefficient $(-0.4)$ between the annual mean of the precipitation rate and the climatic index AO over the western part of KSA. As illustrated in Figure 7(f) and Table 1.

6) It is clear that a notably positive correlation coefficient $(+0.3)$ between the outgoing longwave radiation mainly over the central part of KSA and the climatic index AO. As shown in Figure 7(g) and Table 1.

\subsubsection{The Relationship between the Climatic Parameters over KSA and the SOI Index}

1) For the annual mean of air temperature at $1000 \mathrm{hpa}$ level, it is clear that there is a nun significant negative correlation coefficient exist between the 1000 hpa level air temperature $(-0.1)$ over the southern part of KSA and the Southern 


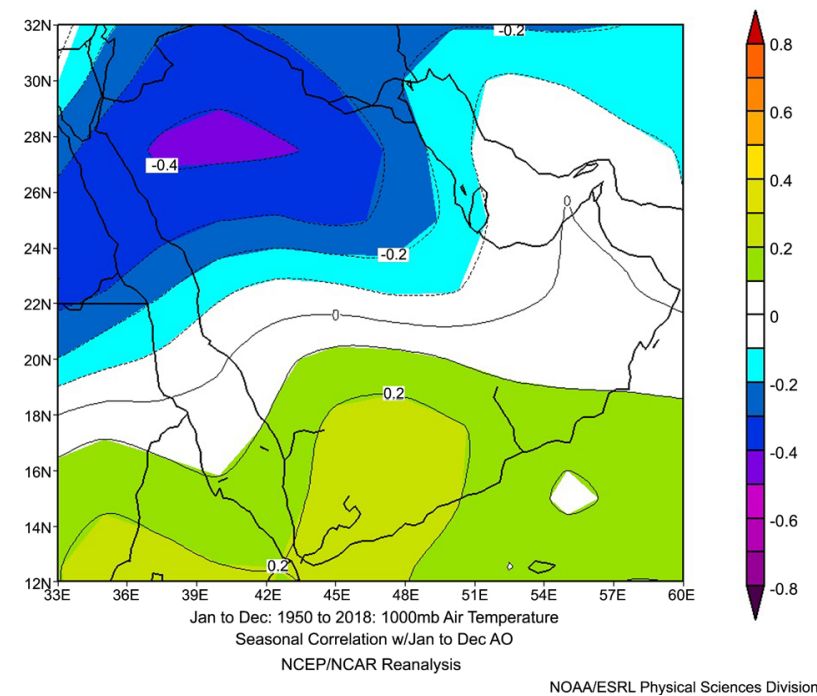

(a)

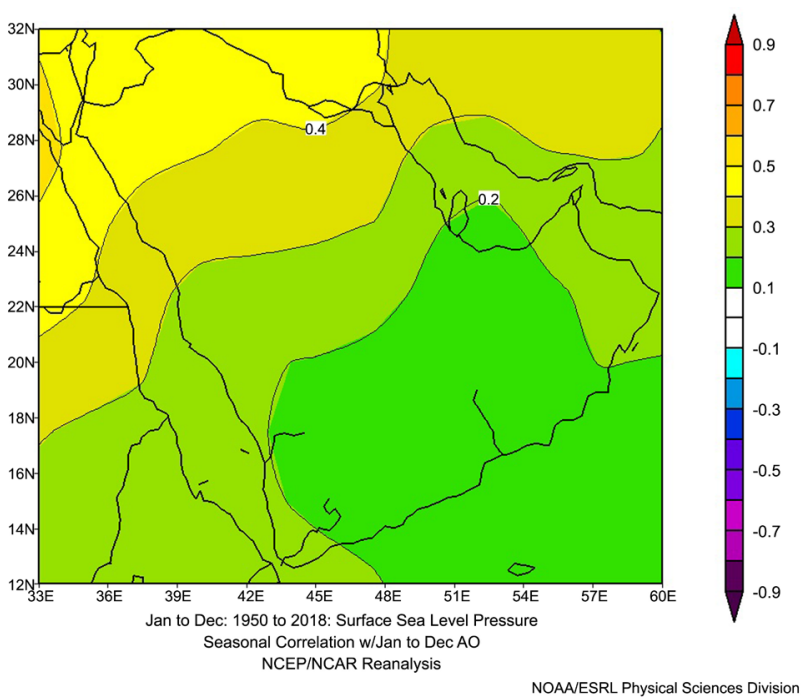

(c)

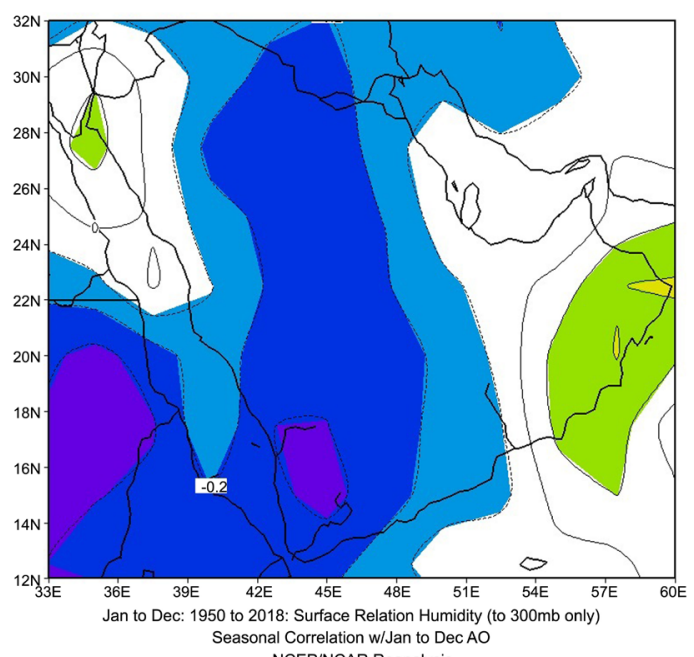
NCEPINCAR Reanalysis

(e)

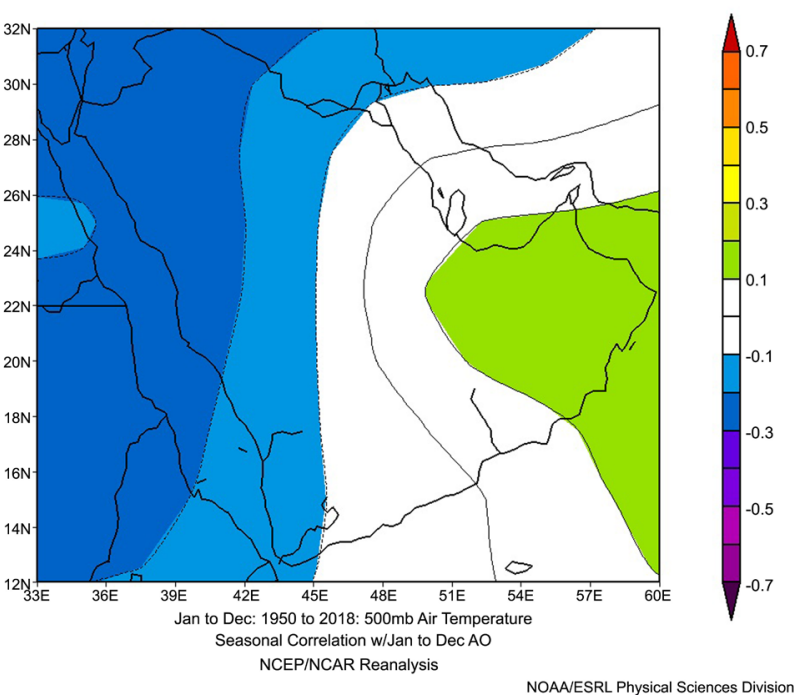

(b)

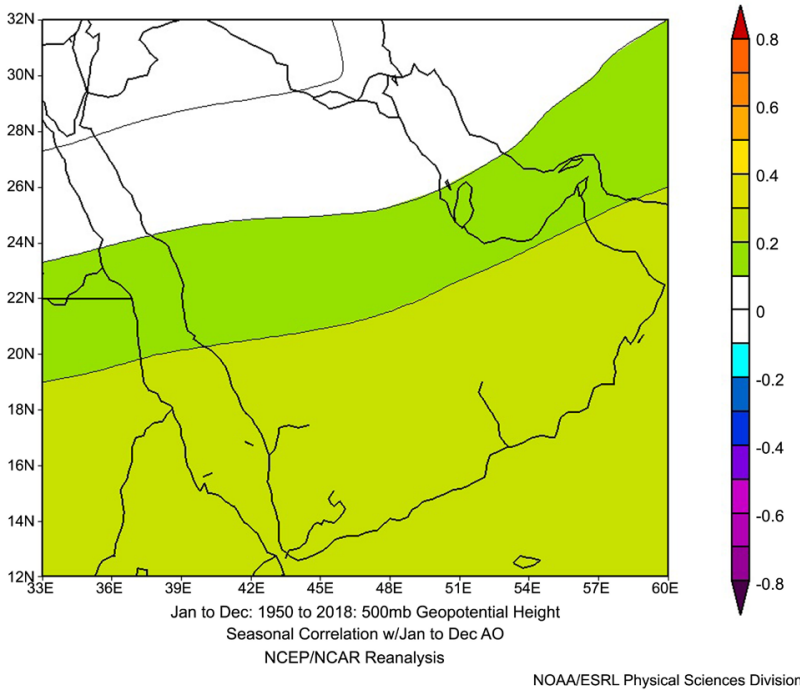

(d)

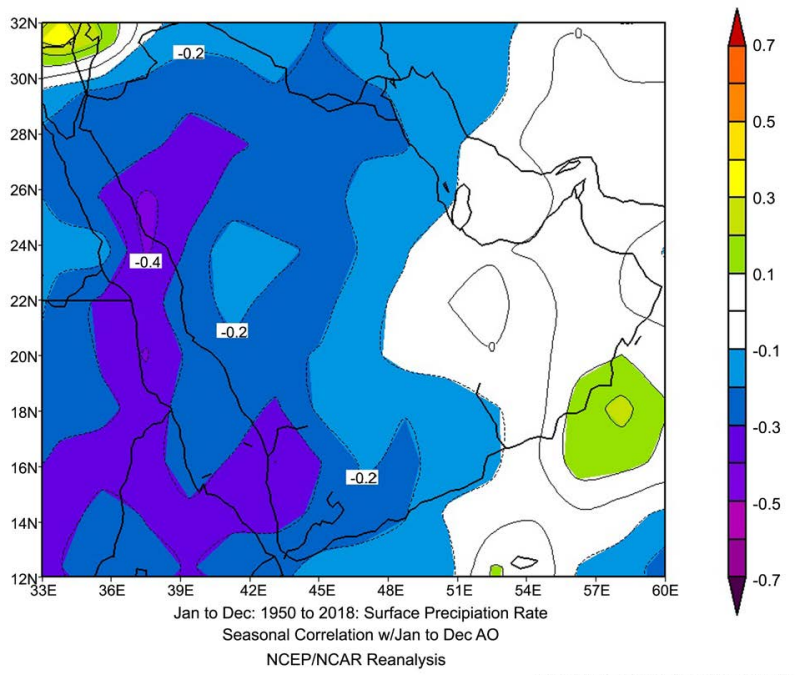

NOAA/ESRL Physical Sciences Division

(f) 


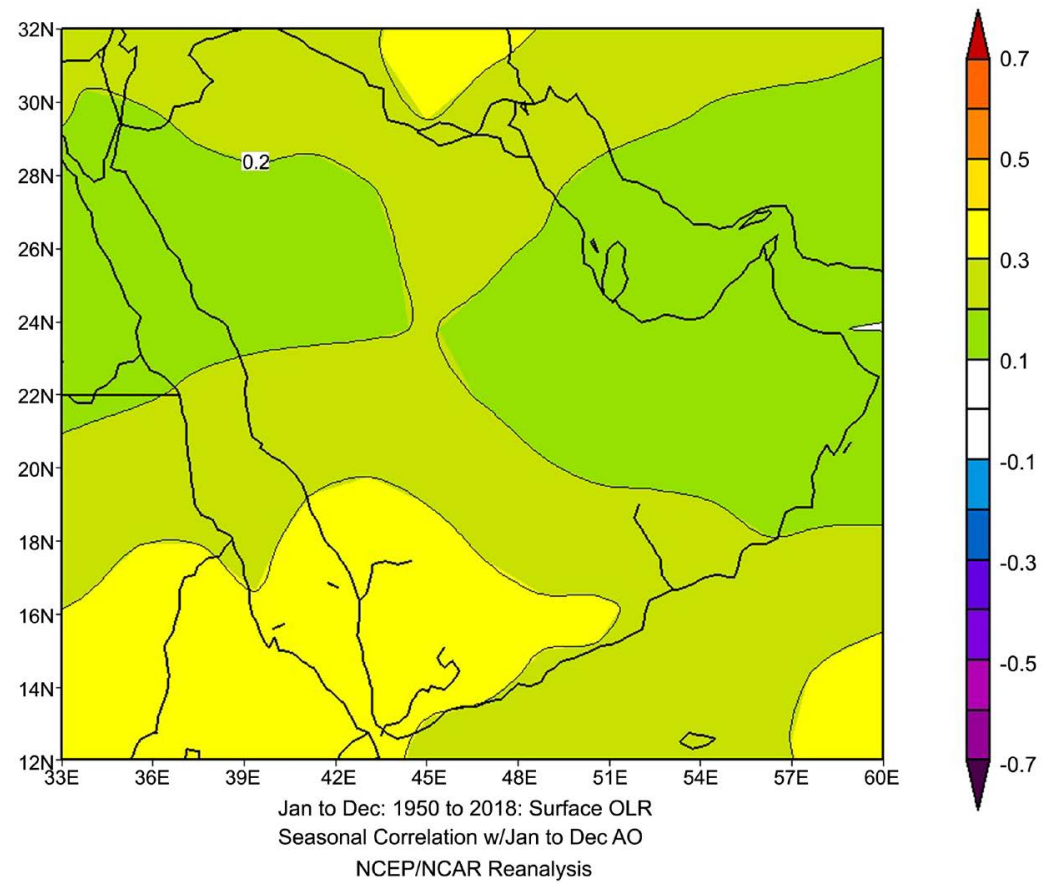

(g)

Figure 7. The composite of correlation coefficient between the annual distribution of climatic parameters (TEMP1000 HPA, TEMP500 HPA, MSLP, GPH500 HPA, RH, PRECIP and OLR) over KSA and the climatic index AO through the period (1950-2018).

Oscillation Index SOI. See Figure 8(a) and Table 1. In addition to that there is a nun significant negative correlation of $(-0.2)$ between the annual mean temperature at $500 \mathrm{hpa}$ level and the NAO over the northern part of KSA through the study period (1948-2018) as clear from Figure 8(b) and Table 1.

2) The value of correlation coefficient between the mean annual of mean sea level pressure is a strong significant negative correlation $(-0.6)$ with the climatic index SOI over the eastern part of KSA. As it shown from, Figure 8(c) and Table 1.

3) There is a significant negative correlation of $(-0.3)$ between the mean annual values of geopotential height at level of $500 \mathrm{hpa}$ and the climatic index SOI over the southern part of KSA as clear from Figure 8(d) and Table 1.

4) It is found that there is a negative nun significant correlation coefficient $(-0.2)$ between the annual mean of the relative humidity and the climatic index SOI over the western part of KSA. As illustrated in Figure 8(e) and Table 1.

5) For the precipitation rate it is found that there is a nun significant negative correlation coefficient $(-0.2)$ between the annual mean of the precipitation rate and the climatic index SOI over the western central part of KSA. As illustrated in Figure 8(f) and Table 1.

6) It is found that a nun significant correlation coefficient $(+0.1)$ between the outgoing longwave radiation over the south of KSA and the climatic index SOI mainly over the northern part of KSA. As shown in Figure 8(g) and Table 1. 


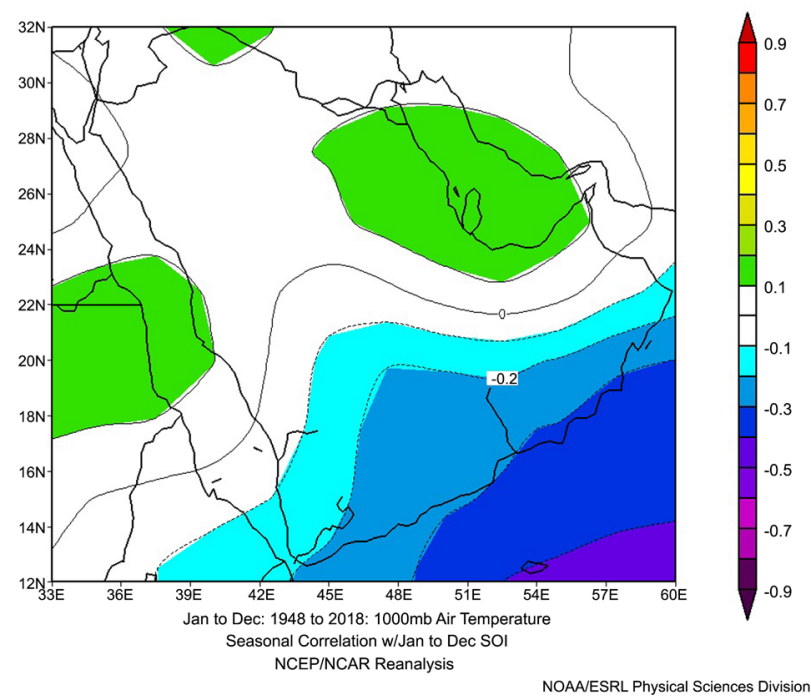

(a)

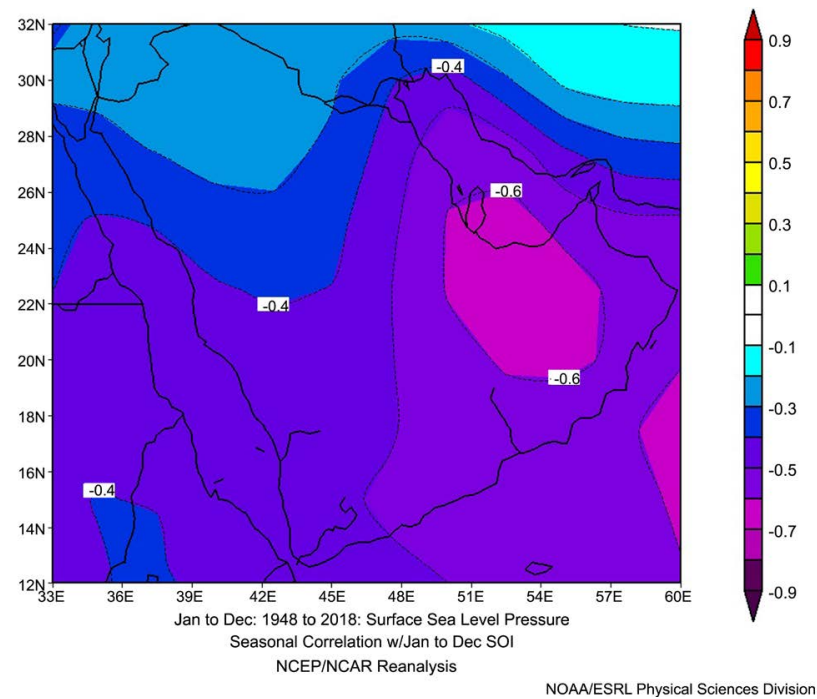

(c)

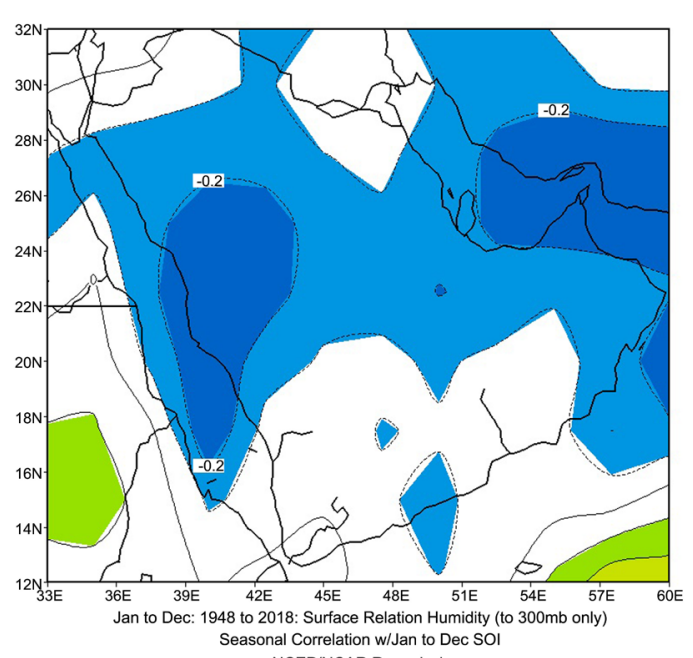

NCEPINCAR Reanalysis

(e)

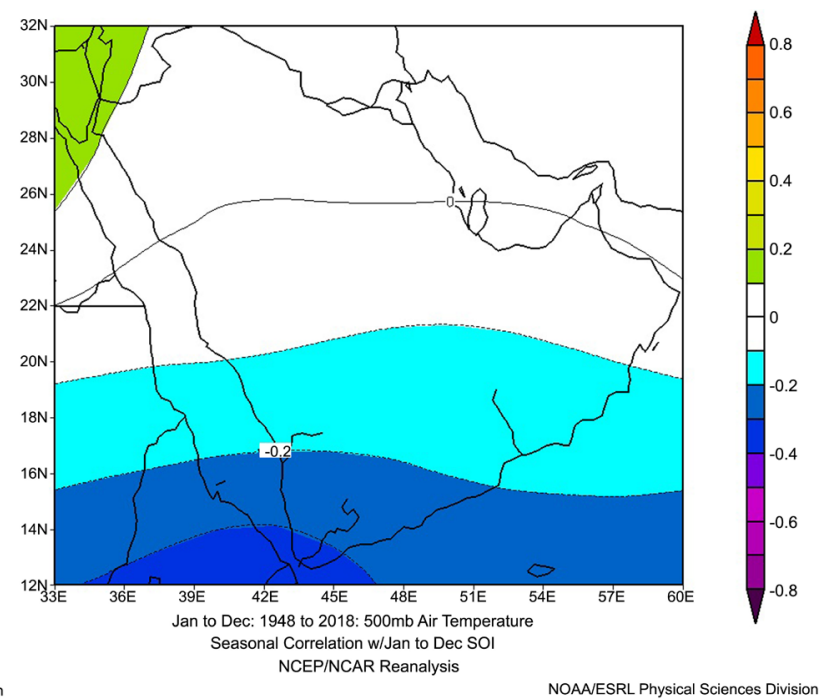

(b)

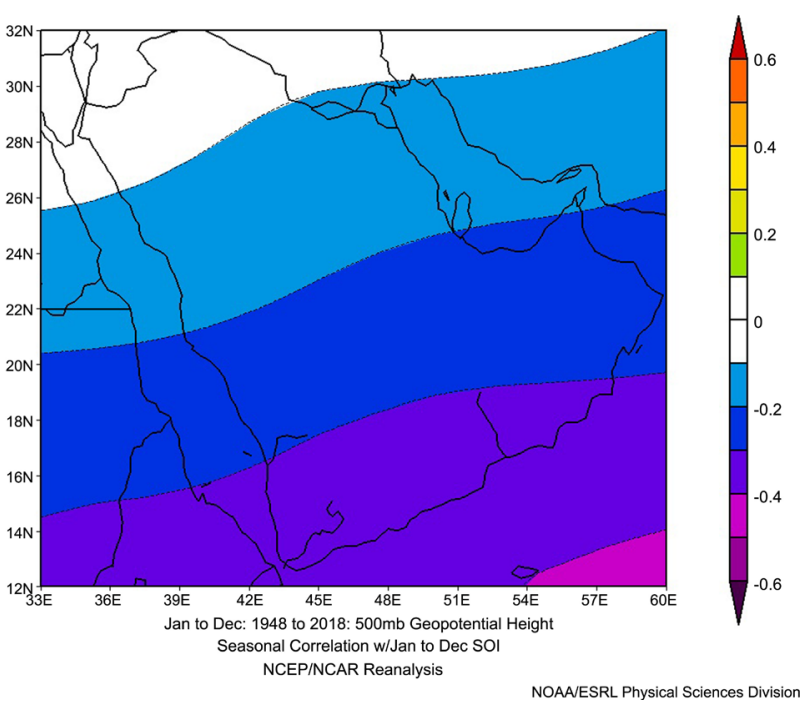

(d)

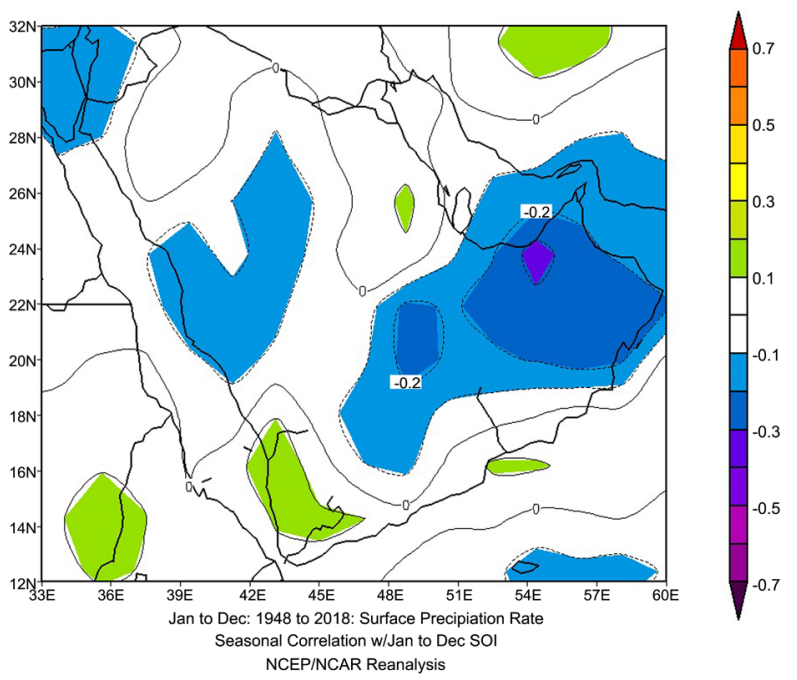

NOAAIESRL Physical Sciences Division

(f) 


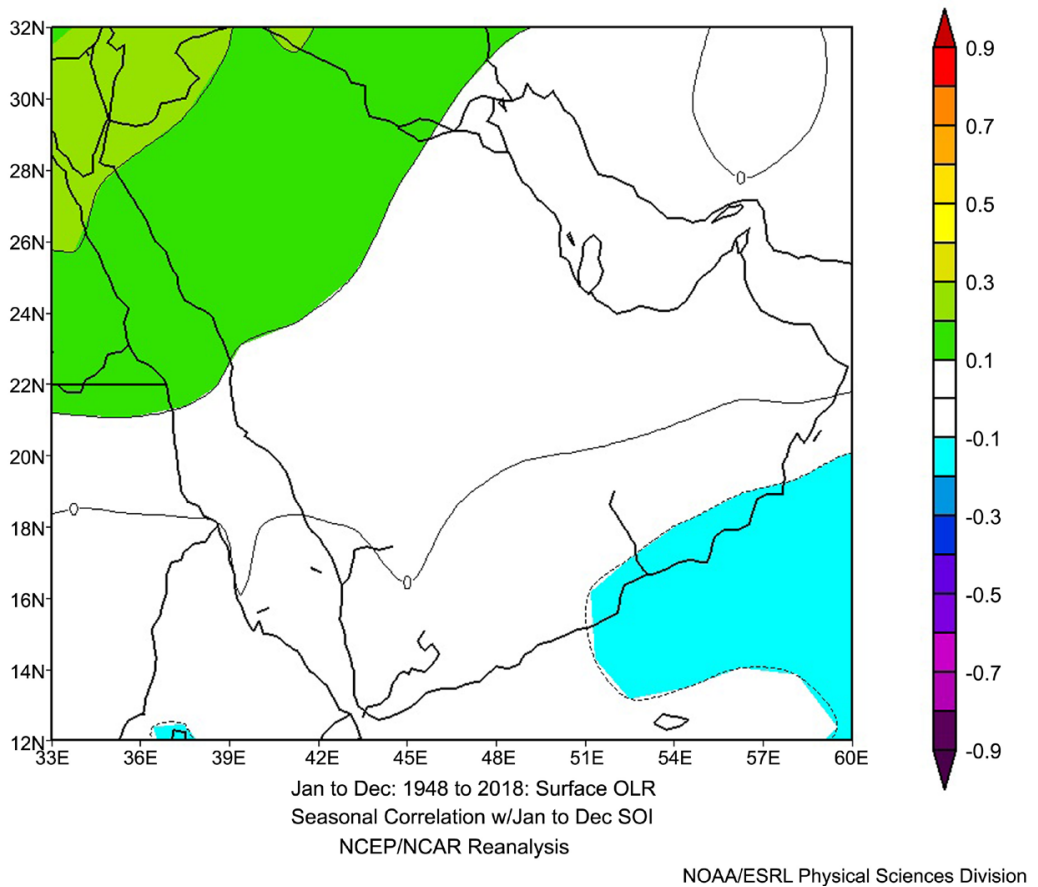

(g)

Figure 8. The composite of correlation coefficient between the annual distribution of climatic parameters (TEMP1000 HPA, TEMP500 HPA, MSLP, GPH500 HPA, RH, PRECIP and OLR) over KSA and the climatic index SOI through the period (1948-2018).

\subsubsection{The Relationship between the Climatic Parameters over KSA and the NIN03.4 Index}

1) For the annual mean of air temperature at $1000 \mathrm{hpa}$ level, it is clear that there is a positive significant correlation coefficient exist between the 1000 hpa level air temperature $(+0.3)$ over the southern part of KSA and the nino3.4 index. See Figure 9 (a) and Table 1. Meanwhile, there is a nun significant positive correlation of $(+0.2)$ between the annual mean temperature at 500 hpa level and the nino3.4 index over the KSA through the study period (1948-2018) as clear from Figure 9 (b) and Table 1.

2) The value of correlation coefficient between the mean annual of mean sea level pressure is a strong value $(+0.5)$ with the nino3.4 index over the KSA through the period (1948-2018). As it shown from, Figure 9(c) and Table 1.

3) There is a positive outstanding correlation of $(+0.4)$ between the mean annual values of geopotential height at level of $500 \mathrm{hpa}$ and the nino3.4 index over the central part of KSA as clear from Figure $9(\mathrm{~d})$ and Table 1.

4) It found that there is a nun significant positive correlation coefficient $(+0.2)$ between the annual mean of the relative humidity and the nino3.4 index over the KSA. As illustrated in Figure 9(e) and Table 1.

5) For the precipitation rate, it is noticed that there is a significant positive correlation coefficient $(+0.3)$ between the annual mean of the precipitation rate and the nino3.4 index over the western central part of the KSA. As illustrated in Figure $9(f)$ and Table 1. 


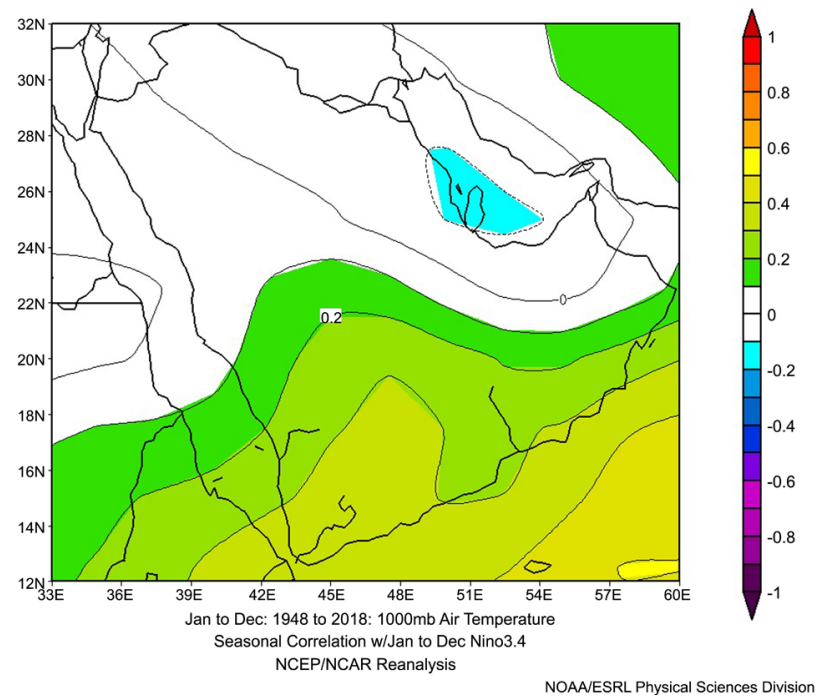

(a)

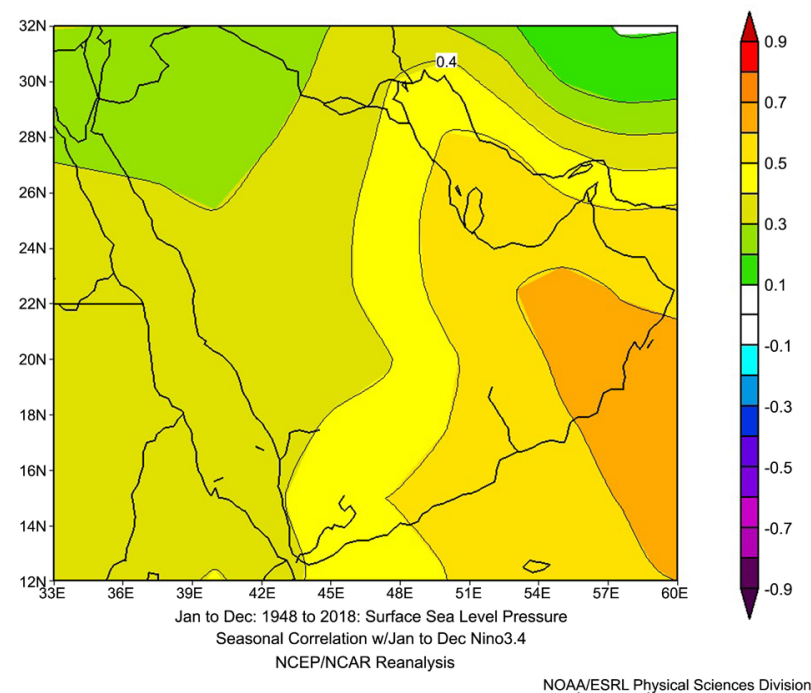

(c)

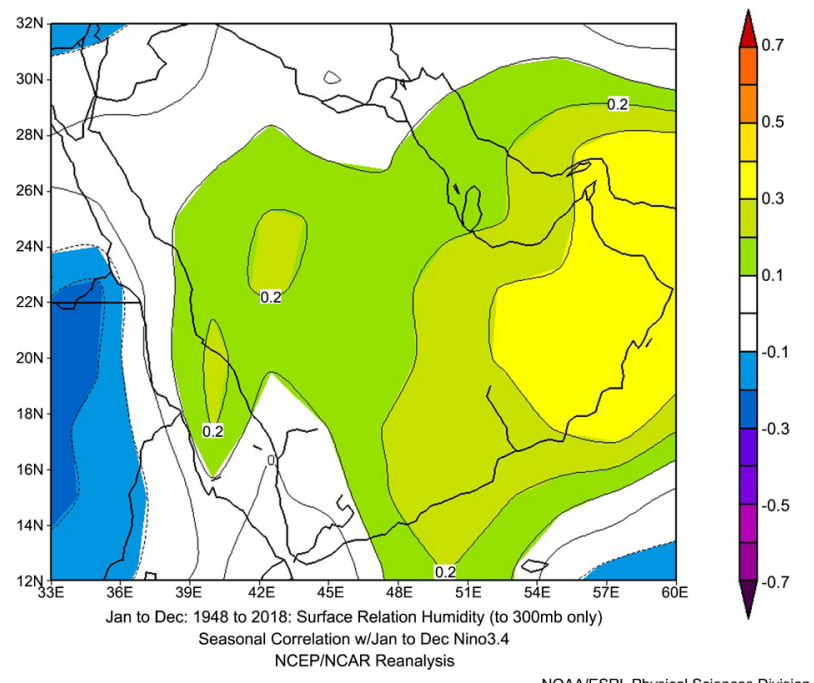

(e)

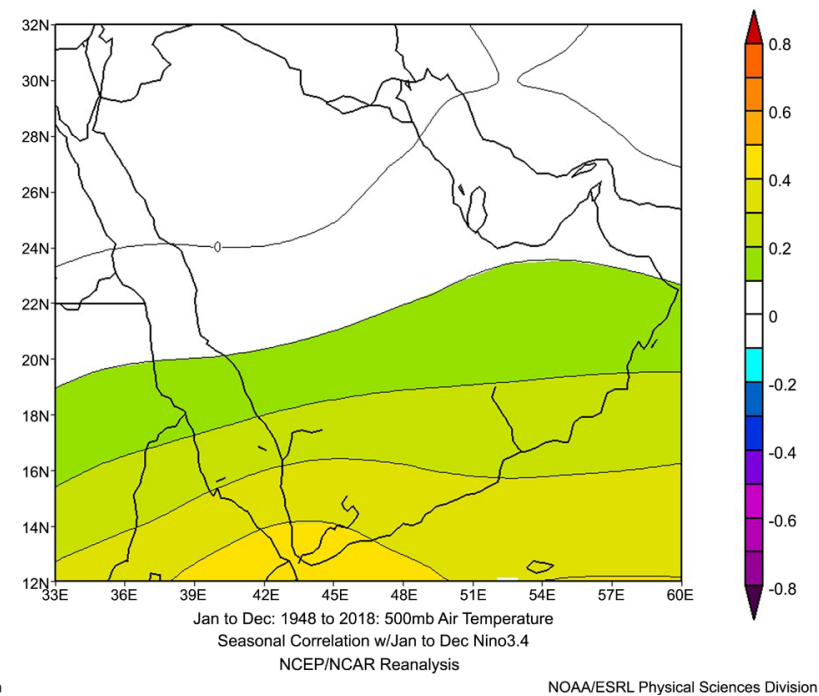

(b)

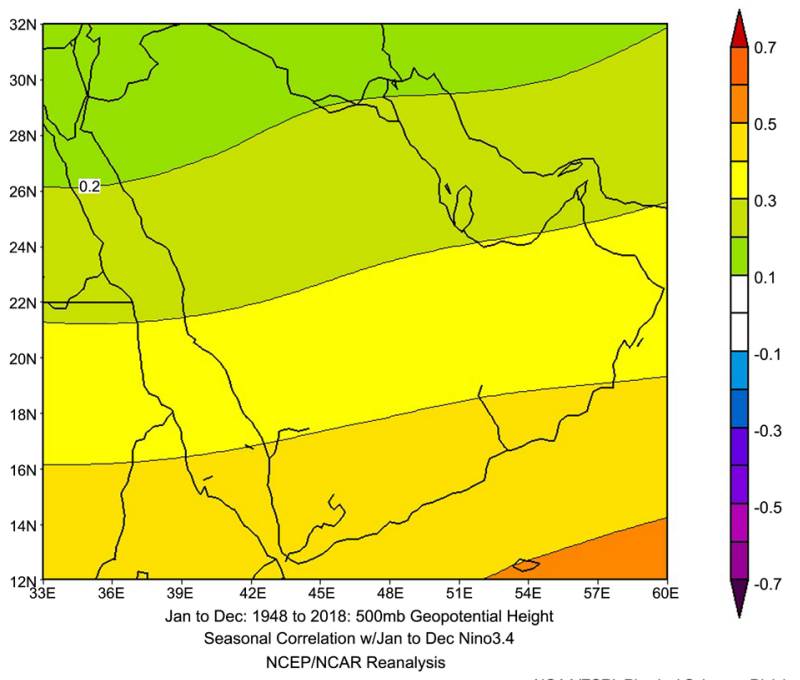

(d)

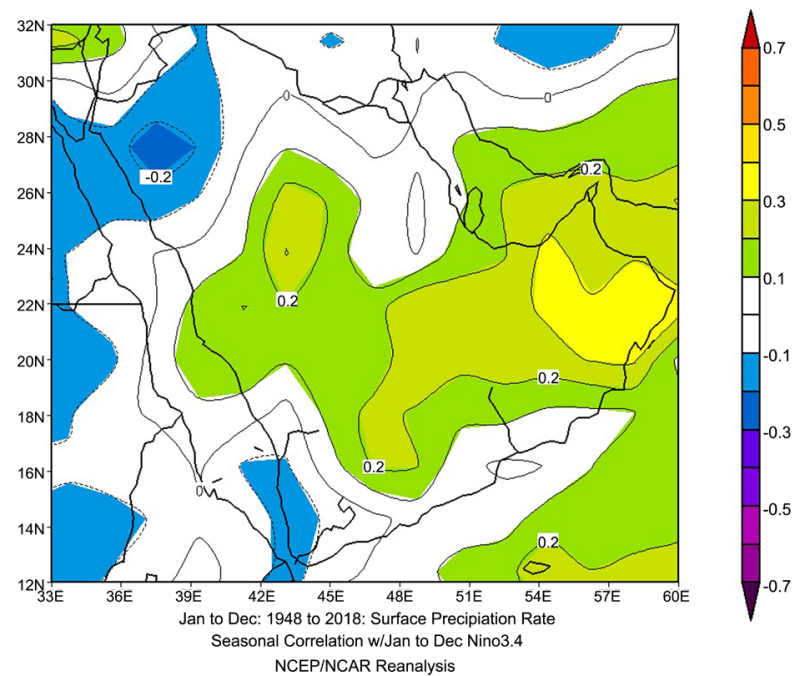

(f) 


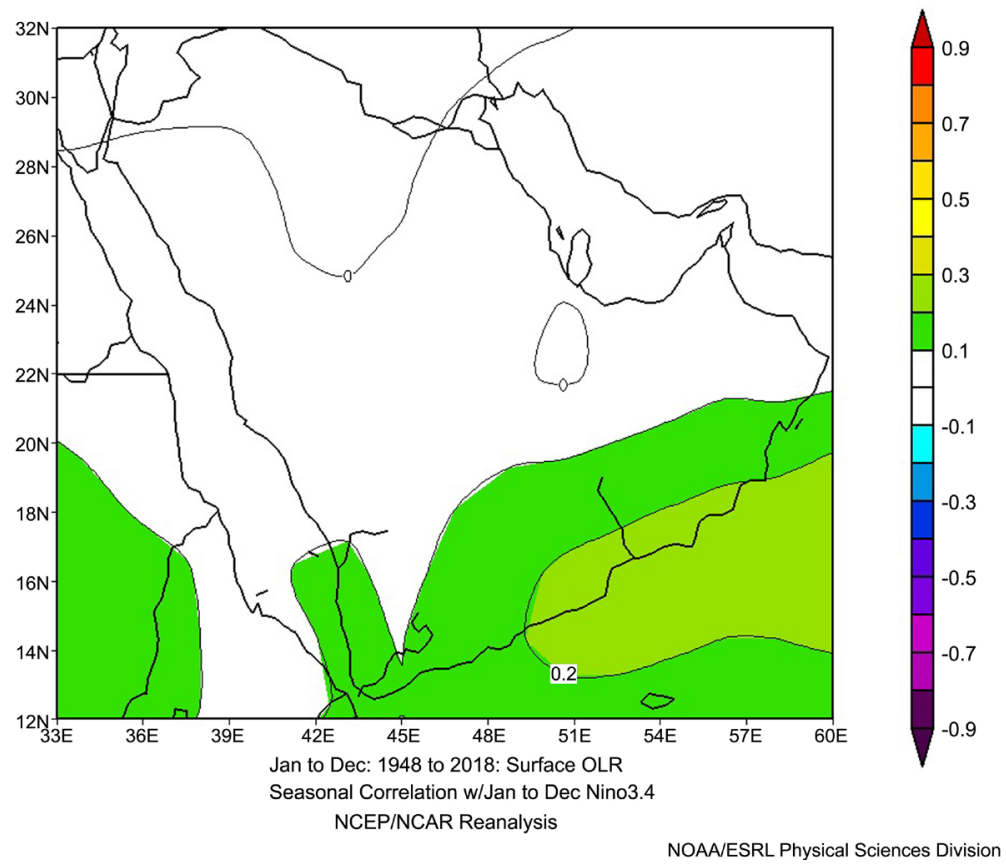

(g)

Figure 9. The composite of correlation coefficient between the annual distribution of climatic parameters (TEMP1000 HPA, TEMP500 HPA, MSLP, GPH500 HPA, RH, PRECIP and OLR) over KSA and the climatic index NINO3.4 through the period (1948-2018).

6) It is clear that there is no any correlation found between the outgoing longwave radiation over the KSA and the nino3.4 index. As shown in Figure $9(\mathrm{~g})$ and Table 1.

\subsubsection{The Relationship between the Climatic Parameters over KSA and the GMST Index}

1) For the annual mean of air temperature at $1000 \mathrm{hpa}$ level, it is clear that there is a very high positive significant correlation coefficient exist between the 1000 hpa level air temperature (+0.8) mainly over the southwest part of KSA and the Global Mean of Surface Temperature (GMST). See Figure 10(a) and Table 1. In addition to that there is a significant positive correlation of $(+0.5)$ between the annual mean temperature at $500 \mathrm{hpa}$ level and the GMST over the eastern part of KSA through the study period (1948-2018) as clear from Figure 10(b) and Table 1.

2) The value of correlation coefficient between the mean annual of mean sea level pressure is $(+0.5)$ with the GMST over the northern part of the KSA through the period (1948-2018). As it shown from, Figure 10(c) and Table 1.

3) There is a very high positive significant correlation of $(+0.8)$ between the mean annual values of geopotential height at level of $500 \mathrm{hpa}$ and the GMST over the KSA as clear from Figure 10(d) and Table 1.

4) It is found that there is a negative significant correlation coefficient $(-0.5)$ between the annual mean of the relative humidity and the GMST over the central part of KSA. As illustrated in Figure 10(e) and Table 1. 


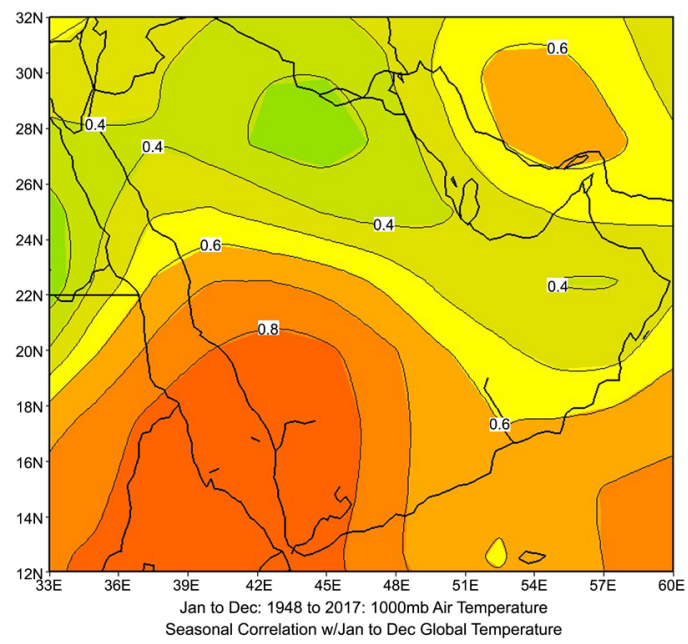

NCEP/NCAR Reanalysis

(a)

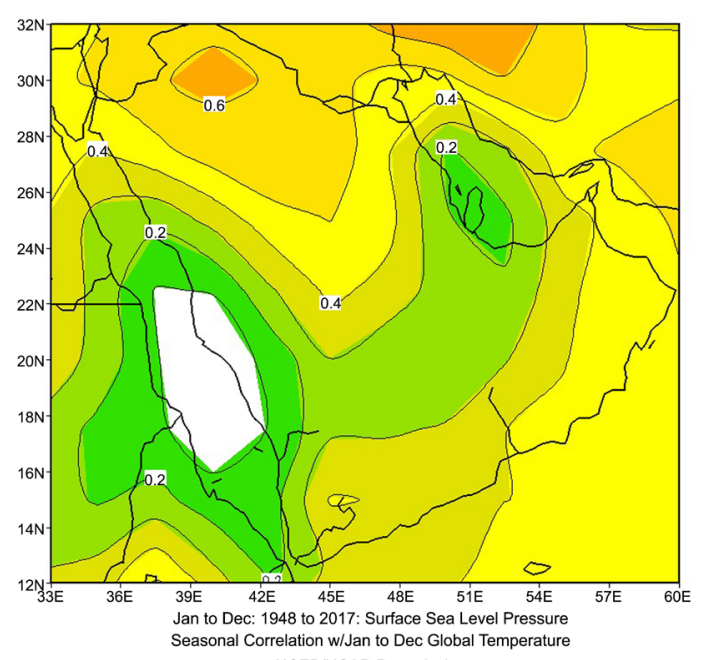
NCEPINCAR Reanalysis

(c)

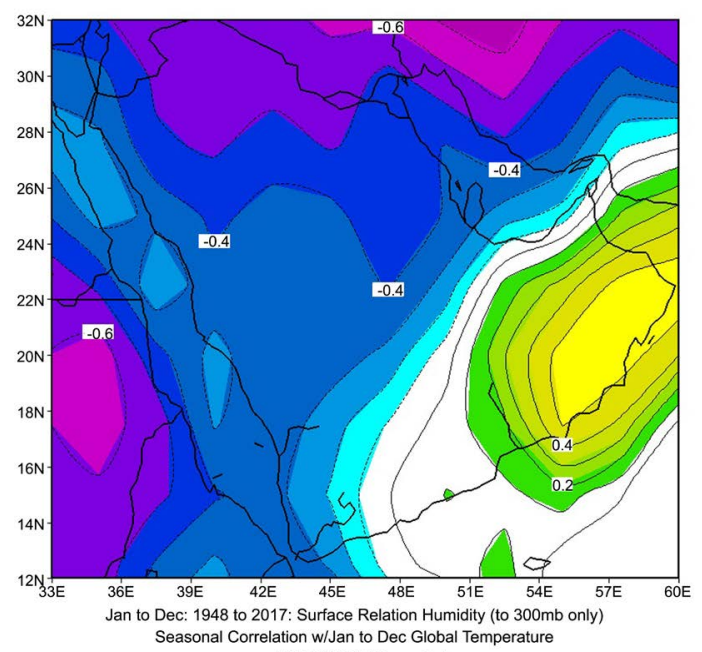
NCEP/NCAR Reanalysis

NOAAESRL Physical Sciences Division

(e)
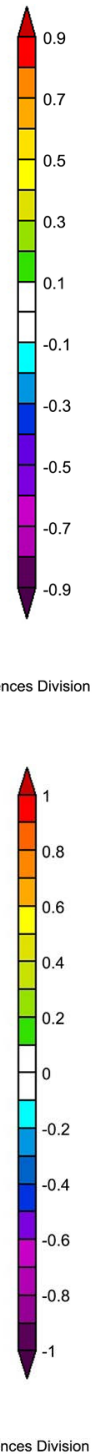
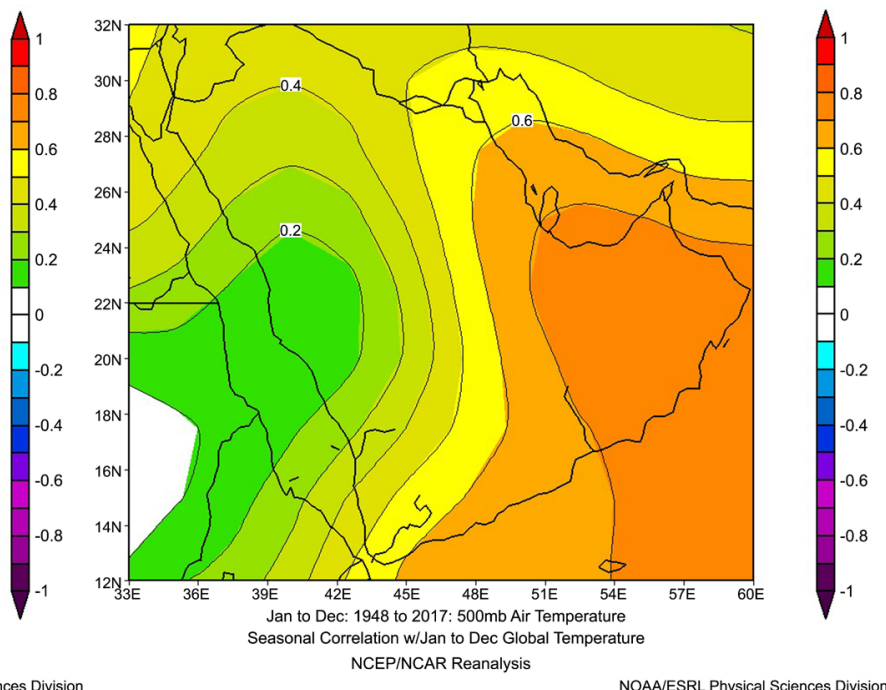

(b)

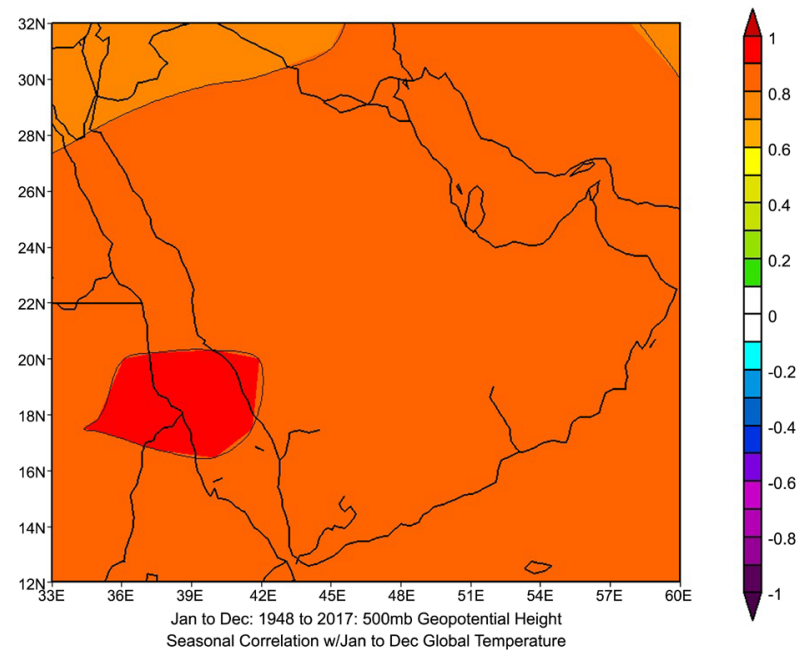

(d)

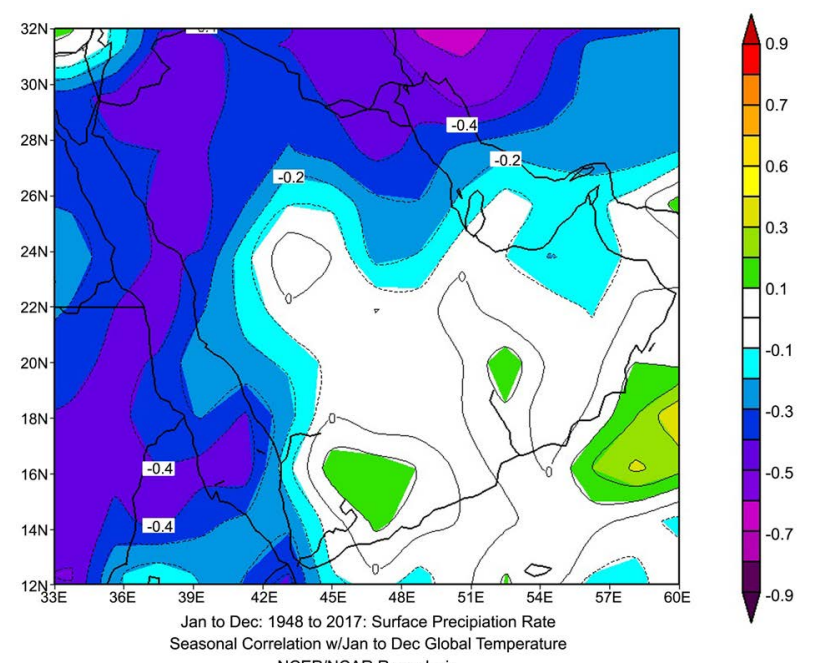
NCEPINCAR Reanalysis

NOAAJESRL Physical Sciences Division

(f) 


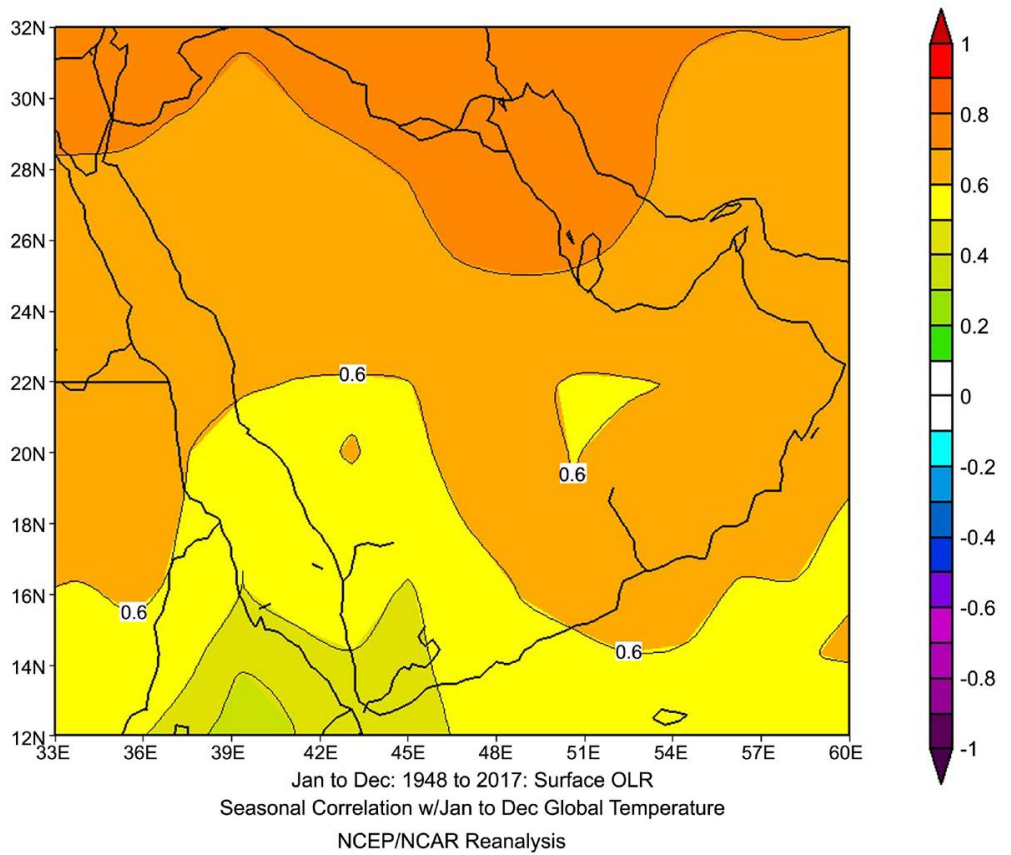

(g)

Figure 10. The composite of correlation coefficient between the annual distribution of climatic parameters (TEMP1000 HPA, TEMP500 HPA, MSLP, GPH500 HPA, RH, PRECIP and OLR) over KSA and the climatic index GTEMP through the period (1948-2018)

5) For the precipitation rate it is found that there is a significant negative correlation coefficient $(-0.3)$ between the annual mean of the precipitation rate and the GMST over the northern part of KSA. As illustrated in Figure 10(f) and Table 1 .

$6)$ It is found that a notably very high positive significant correlation coefficient $(+0.8)$ between the outgoing longwave radiation over the northern and eastern part of KSA and the GMST. As shown in Figure $10(\mathrm{~g})$ and Table 1.

From the above results, it becomes clear that the annual weather and climatic parameters over KSA vary from year to year dramatically. The notable increase in temperature and pressure and outgoing longwave radiation trend recorded through the study period (1948-2018). In contradicting to that, there is an annual decrease of surface humidity and precipitation rate through the study period. It found that the annual mean air temperature at level $1000 \mathrm{hpa}$ is highly correlated to climatic indices NAO, AO, NINO3.4 and GMST through the study period. The annual mean air temperature at level 500 hpa is high correlate to climatic indices NAO, AO and GMST. The results uncovered that the annual mean sea level pressure over KSA is highly significant influenced by all studied climatic indices. Meanwhile, it is clear that the annual geopotential height values at level 500 hpa affected by SOI, NINO3.4 and GMST. The annual values of surface relative humidity over KSA have correlated more significant with AO and GMST through the study period. For precipitation rate it found that, there is a significant correlation coefficient between the precipitation over KSA and NAO, 
AO, NINO3.4 and GMST through the study period. The mean annual values of outgoing longwave radiation over KSA have a significant correlation with AO and GMST. One can conclude that the KSA climate varies according to the northern and southern hemisphere interactions. Moreover, the highest recorded significant correlation was between the mean annual of climatic parameters over KSA and the global mean of surface air temperature through the period of study (1948-2018).

\section{Acknowledgements}

The author hopes to thank the NOAA/ESRL Physical Sciences Division. Data and Images provided by the NOAA/ESRL Physical Sciences Division, Boulder Colorado from their Web site at http://www.esrl.noaa.gov/psd/.

\section{Conflicts of Interest}

The author declares no conflicts of interest regarding the publication of this paper.

\section{References}

Abdullah, M. A., \& Al-Mazroui, M. A. (1998). Climatological Study of the South-Western Region of Saudi Arabia. I. Rainfall Analysis. Climate Research, 9, 213-223. https://doi.org/10.3354/cr009213

Adiku, S. G. K., \& Stone R. C. (1995). Using the Southern Oscillation Index for Improving Rainfall Prediction and Agricultural Water Management in Ghana. Agricultural Water Management, 29, 85-100. https://doi.org/10.1016/0378-3774(95)01181-1

Almazroui, M. (2012). Temperature Variability over Saudi Arabia and its Association with Global Climate Indices. JKAU: The Meteorology, Environment and Arid Land Agriculture Journal of King Abdulaziz University, 23, 85-108. https://doi.org/10.4197/Met.23-1.6

Almazroui, M., Nazrul, I. M., Jones, P. D., Athar, H., \& Ashfaqur, R. M. (2012). Recent Climate Change in the Arabian Peninsula: Seasonal Rainfall and Temperature Climatology of Saudi Arabia for 1979-2009. Atmospheric Research, 111, 29-45. https://doi.org/10.1016/j.atmosres.2012.02.013

Ambaum, M. H. P., Hoskins, B. J., \& Stephenson, D. B. (2001). Arctic Oscillation or North Atlantic Oscillation? Journal of Climate, 14, 3495-3507. https://doi.org/10.1175/1520-0442(2001)014<3495:AOONAO>2.0.CO;2

Athar, H. (2015). Teleconnection and Variability in Observed Rainfall over Saudi Arabia during 1978-2010. Atmospheric Science Letters, 16, 373-379.

https://doi.org/10.1002/asl2.570

Barriendos, M., \& Llasat, M. C. (2003). The Case of "Maldá" Anomaly in the Western Mediterranean Basin (AD 1760-1800): An Example of a Strong Climatic Variability. Climatic Change, 61, 191-216. https://doi.org/10.1023/a:1026327613698

Choi, K., \& Byun, H. (2010). Possible Relationship between Western North Pacific Tropical Cyclone Activity and Arctic Oscillation. Theoretical and Applied Climatology, 100, 261-274. https://doi.org/10.1007/s00704-009-0187-9

Cobon, D. H., \& Toombs, N. R. (2013). Forecasting Rainfall Based on the Southern Oscillation Index Phases at Longer Lead-Times in Australia. The Rangeland Journal, 35, 
373-383. https://doi.org/10.1071/RJ12105

Diaconis, P., \& Efron, B. (1983). Computer Intensive Methods in Statistics. Scientific American, 248, 116-130. https://doi.org/10.1038/scientificamerican0583-116

Donat, M. G. et al. (2013). Changes in Extreme Temperature and Precipitation in the Arab Region: Long-Term Trends and Variability Related to ENSO and NAO. International Journal of Climatology, 34, 581-592. http://wileyonlinelibrary.com https://doi.org/10.1002/joc.3707

El-Nesr, M., Alazba, A., \& Abu-Zreig, M. (2010) Analysis of Evapotranspiration Variability and Trends in the Arabian Peninsula. American Journal of Environmental Sciences, 6, 535-547. https://doi.org/10.3844/ajessp.2010.535.547

Goddard, L., \& Dilley, M. (2005). El Niño: Catastrophe or Opportunity. Journal of climate, 18, 651-665. https://doi.org/10.1175/jcli-3277.1

Gong, D. Y., \& Ho, C. H. (2003). Arctic Oscillation Signals in the East Asian Summer Monsoon. Journal of Geophysical Research: Atmospheres, 108, 4066.

https://doi.org/10.1029/2002JD002193

Gong, D., \& Wang, S. (1999). Definition of the Antarctic Oscillation Index. Geophysical Research Letters, 26, 459-462. https://doi.org/10.1029/1999GL900003

Hafez, Y. (2016). Study on the Relationship between the Oceanic Nino Index and Surface Air Temperature and Precipitation Rate over the Kingdom of Saudi Arabia. Journal of Geoscience and Environment Protection, 4, 146-162. http://www.scirp.org/journal/gep https://doi.org/10.4236/gep.2016.45015

Hafez, Y. (2018). A Recent Study of Seasonal and Interannual Climate Variability over the Eastern Mediterranean Region. Journal of Geoscience and Environment Protection, 6, 132-151. https://doi.org/10.4236/gep.2018.61009

Hafez, Y. Y. (2008). The Teleconnection between the Global Mean Surface Air Temperature and Precipitation over Europe. International Journal of Meteorology, 33, 230-237.

Hafez, Y. Y., \& Robaa, S. M. (2008). The Relationship between the Mean Surface Air Temperature in Egypt and NAO Index and ENSO. The Open Atmospheric Science Journal, 2, 8-17. https://doi.org/10.2174/1874282300802010008

Hag-Elsafi, S., \& El-Tayib, M. (2016). Spatial and Statistical Analysis of Rainfall in the Kingdom of Saudi Arabia from 1979 to 2008. Weather, 71, 262-266. https://doi.org/10.1002/wea.2783

Hasanean, H., \& Almazroui, M. (2015). Rainfall: Features and Variations over Saudi Arabia: A Review. Climate, 3, 578-626. https://doi.org/10.3390/cli3030578

Hines, K. M., \& Bromwich, D. H. (2002). A Pole to Pole West Pacific Atmospheric Teleconnection during August. Journal of Geophysical Research: Atmospheres, 107, 4359. https://doi.org/10.1029/2001JD001335

Hurrell, J. W. (1995). Decadal Trends in the North Atlantic Oscillation: Regional Temperatures and Precipitation. Science, 269, 676-679.

https://doi.org/10.1126/science.269.5224.676

Iona, A., Theodorou, A., Sofianos, S., Watelet, S., Troupin, C., \& Beckers, J. (2015). Mediterranean Sea Climatic Indices: Monitoring Long-Term Variability and Climate Changes. Earth System Science Data, 10, 1829-1842.

https://doi.org/10.5194/essd-10-1829-2018

Kalnay, E., Kanamitsu, M., Kistler, R. et al. (1996). The NCEP/NCAR 40-Year Reanalysis Project. Bulletin of American Meteorological Society, 77, 437-471. https://doi.org/10.1175/1520-0477(1996)077<0437:TNYRP>2.0.CO;2

Kang, I., Rashid, I. U., Kucharski, F., Almazroui, M., \& Alkhalaf, A. K. (2015). Multide- 
cadal Changes in the Relationship between ENSO and Wet-Season Precipitation in the Arabian Peninsula. Journal of Climate, 28, 4743-4752.

https://doi.org/10.1175/JCLI-D-14-00388.1

Kutzbach, J. E. (1970). Large-Scale Features of Monthly Mean Northern Hemisphere Anomaly Maps of Sea-Level Pressure. Monthly Weather Review, 98, 708-716. https://doi.org/10.1175/1520-0493(1970)098<0708:LSFOMM>2.3.CO;2

Kwarteng, A. Y., Dorvlo, A. S., \& Kumar, G. T. V. (2009). Analysis of a 27-Year Rainfall Data (1977-2003) in the Sultanate of Oman. International Journal of Climatology, 29, 605-617. https://doi.org/10.1002/joc.1727

Livezey, R. E., \& Chen, W. Y. (1983). Statistical Field Significance and Its Determination by Monte Carlo Techniques. Monthly Weather Review, 111, 46-59. https://doi.org/10.1175/1520-0493(1983)111<0046:SFSAID>2.0.CO;2

Lorenz, E. N. (1950). Seasonal and Irregular Variations of the Northern Hemisphere Sea-Level Pressure Profile. Journal of Meteorology, 8, 52-59. https://doi.org/10.1175/1520-0469(1951)008<0052:SAIVOT>2.0.CO;2

Mashat, A., \& Abdel Basset, H. (2011). Analysis of Rainfall over Saudi Arabia. JKAU: The Meteorology, Environment and Arid Land Agriculture Journal of King Abdulaziz University, 22, 59-78. https://doi.org/10.4197/met

Overland, J. E., \& Wang, M. (2005). The Arctic Climate Paradox: The Recent Decrease of the Arctic Oscillation. Geophysical Research Letters, 32, L06701. https://doi.org/10.1029/2004GL021752

Philips, J. L. (1996). How to Think about Statistics (5th ed.). New York: W. H. Freeman.

Saeed, S., \& Almazroui, M. (2019). Impacts of Mid-Latitude Circulation on Winter Precipitation over the Arabian Peninsula. Climate Dynamics, 1-12. https://doi.org/10.1007/s00382-019-04862-6

Sun, J., \& Wang, H. (2006). Relationship between Arctic Oscillation and Pacific Decadal Oscillation on Decadal Timescale. Chinese Science Bulletin, 51, 75-79.

Tarawneh, Q. Y., \& Chowdhury, S. (2018). Trends of Climate Change in Saudi Arabia: Implications on Water Resources. Climate, 6, 8. https://doi.org/10.3390/cli6010008

Thompson, D. W. J., \& Wallace, J. M. (1998). The Arctic Oscillation Signature in Wintertime Geopotential Height and Temperature Fields. Geophysical Research Letters, 25, 1297-1300. https://doi.org/10.1029/98GL00950

Thompson, D. W. J., Wallace, J. M., \& Hegerl, G. C. (2000). Annular Modes in the Extratropical Circulation. Part II: Trends. Journal of Climate, 13, 1018-1036. https://doi.org/10.1175/1520-0442(2000)013<1018:AMITEC>2.0.CO;2

Tularam, G. A. (2010). Relationship between El Nino Southern Oscillation Index and Rainfall (Queensland, Australia). International Journal of Sustainable Development and Planning, 5, 378-391. https://doi.org/10.2495/SDP-V5-N4-378-391

Wallace, J. M. (2000). North Atlantic Oscillation/Annular Mode: Two Paradigms-One Phenomenon. Quarterly Journal of the Royal Meteorological Society, 126, 791-805.

Wallace, J. M., \& Gutzler, D. S. (1981). Teleconnections in the Geopotential Height Field during the Northern Hemisphere Winter. Monthly Weather Review, 109, 784-812. https://doi.org/10.1175/1520-0493(1981)109<0784:TITGHF>2.0.CO;2 